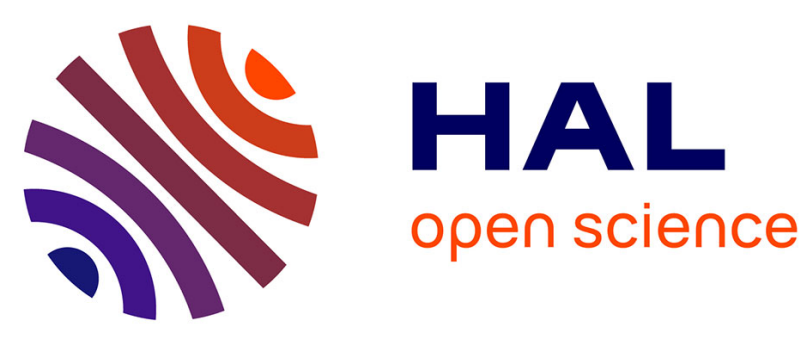

\title{
Modeling of Semisolid Flow
}

Veronique Favier

\section{- To cite this version:}

Veronique Favier. Modeling of Semisolid Flow. Comprehensive Materials Processing, 5, Elsevier, pp.191-209, 2014, 978-008096533-8. 10.1016/B978-0-08-096532-1.00519-7 . hal-02625821

\section{HAL Id: hal-02625821 \\ https://hal.science/hal-02625821}

Submitted on 26 May 2020

HAL is a multi-disciplinary open access archive for the deposit and dissemination of scientific research documents, whether they are published or not. The documents may come from teaching and research institutions in France or abroad, or from public or private research centers.
L'archive ouverte pluridisciplinaire HAL, est destinée au dépôt et à la diffusion de documents scientifiques de niveau recherche, publiés ou non, émanant des établissements d'enseignement et de recherche français ou étrangers, des laboratoires publics ou privés. 


\section{Modeling of Semisolid Flow}

Favier, Arts et Métiers ParisTech, Paris, France

\section{Nomenclature}

$\nabla()$ - Gradient

$\frac{\mathbf{D}}{\mathbf{D} t}()=\frac{\partial}{\partial t}()+\underline{u} \cdot \nabla()$ Material derivative

$\nabla \cdot()$ - Divergence

$\boldsymbol{\rho}$ - Density of the overall semisolid

$\underline{u}$ - Velocity vector

$\underline{\sigma}-$ Stress tensor

$\underline{\bar{b}}$ - External volume forces

$\underline{\underline{S}}$ - Deviatoric part of stress tensor

$\bar{p}$ - Hydrostatic pressure

$\operatorname{tr}(\underline{\underline{\sigma}})=\sigma_{11}+\sigma_{22}+\sigma_{33}$

$\underline{\underline{I}}$ - Identity tensor

$\boldsymbol{e}$ - Internal specific energy

$\underline{\underline{D}}$ - Strain rate tensor

$\boldsymbol{r}$ - Internal volume heat sources

$q$ - Heat flux vector

$\bar{h}$ - Specific enthalpy $f_{\mathrm{s}}$ - Volume fraction of solid phase

$\boldsymbol{T}$ - Temperature

$\boldsymbol{\eta}$ - Viscosity

$\dot{\gamma}$ - Shear rate

$\boldsymbol{K}, \boldsymbol{K}^{\prime}$ - Material consistency

$\boldsymbol{m}$ - Strain rate sensitivity parameter

$\lambda$-Structural parameter describing the degree

of agglomeration of the solid globules

$\boldsymbol{k}$ - Thermal conductivity

$c_{\mathrm{p}}$ - Specific heat coefficient

$L^{(\mathrm{s} / \mathrm{l})}$ - Latent heat of fusion

$\boldsymbol{h}_{\text {ext }}$ - Heat transfer coefficient

$\underline{n}, \underline{t}-$ Unit normal and tangential vectors

$\tau_{\max }$ - Maximum shear stress in the modified friction Coulomb's law

$K_{\mathrm{s}}$ - Permeability of the porous solid phase

\section{Why Model Semisolid Flow?}

Numerical simulations are very useful to explore the semisolid flow and heat transfers during processing, predict the zones of defects and optimize the processing parameters (load, speed, billet, and die temperatures). They are also of great interest to gain new insight into new technology and new design rules for the best exploitation of semisolid processing. Semisolid processing involves very large deformations (a cylindrical billet is shaped into an engine suspension mounts, for instance) and solidification phenomena from the starting semisolid state to the final solid state. The spatial arrangement of the liquid and solid phases, at the microscopic scale (scale of the microstructure $=10 \mu \mathrm{m}$ ) and at the macroscopic scale (scale of the component $=10 \mathrm{~cm}$ ) can strongly change during processing. In extreme cases, it results in a liquid-solid phase segregation as observed when a sponge filled with water is pressed. Numerical simulations do not take into account all the complicated phenomena occurring during semisolid processing. Even so, they are of great interest to reduce the cost and time-consuming experiments and separately investigate the effect of processing and 
materials parameters on the processing and the final product. Numerical simulations require methods to discretize the studied system and solve the differential equations of the thermomechanical problem. They require models to represent the thermal and mechanical behavior of the material. Models require input rheological and metallurgical data from experiments. And last, specific experiments are needed to verify and validate the numerical simulations. All these items are explained and discussed in the following sections.

\section{General Purpose}

Semisolids are metallic alloys containing solute atoms heated at a temperature between the solidus and the liquidus. They are constituted of two phases: the liquid and solid phases. The mechanical resistance of the liquid and solid phases is different by about 6-9 orders of magnitude. The behavior of semisolid may change from a liquidlike behavior to a solidlike behavior during processing, depending on the solid fraction and spatial distribution of the two phases within the material. That is why both fluid and solid modeling approaches may be used to simulate semisolid processing. Semisolid during processing is considered as a closed continuous thermodynamic system. It is able to exchange energy (heat and work) but not matter with the environment. Its response is controlled by equations of conservation. Fluid and solid approaches are based on the same differential equations of conservation: conservation of mass, conservation of momentum, and conservation of energy. They mainly differ in the type of constitutive equations (elastic-viscoplastic for the solid approach and pure viscous for the liquid approach) used to describe the semisolid behavior and the way to follow a particle throughout a flow: the Lagrangian representation for the solid approach and the Eulerian representation for the fluid approach. The Eulerian representation is more convenient to describe flow. The Lagrangian representation is more appropriate when final properties of the component are of interest (1). The choice between these two approaches is also motivated by the type of semisolid processing. Rheocasting for which the semisolid state is reached by cooling the liquid and the solid fraction is less than 0.5 is usually simulated by continuous fluid dynamics (CFD) codes. Thixoforming for which the semisolid state is reached by reheating the material from the solid state and the solid fraction is greater than 0.5 is usually simulated by solid metal forming-type codes.

Variables such as the density are different for the liquid and solid phases. The velocity of liquid phase is greater than the velocity of the solid phase in the liquid-solid separation (segregation) case. Accounting for these differences rises to two-phase modeling. The laws of conservation, the models, and the input material data are given for both phases. Solving the problem called two-phase modeling is very complicated.

Current commercial codes actually ignore the presence of the two phases at the microscopic scale. The laws of conservation, the models, and the input material data are thus given for a semisolid element. The resulting modeling is called one-phase modeling. A semisolid element is a small 'blob' of semisolid considered as a homogeneous equivalent medium (HEM), which has the same properties as the real and heterogeneous material. This blob of size $D$ contains a large number of solid globules of mean size $d$ to ensure that it statistically represents the material response (Figure 1). If so, the blob is called a representative volume element (RVE). The size $D$ of the blob must be much lower than the part size $L$ in order to consider the RVE as a material element for computational mechanics (Figure 1). The macroscopic (component), mesoscopic (RVE), and microscopic (solid globules) scales are designated as well separated. The fields such as density, velocity, stress tensor, temperature, and enthalpy associated with the RVE represent the average of the local fields over the liquid and solid volume within the blob. Thermomechanical properties such as viscosity, thermal expansion coefficient, and heat capacity are also associated with the RVE. If the equations of conservation are universal (i.e., identical for any thermomechanical system), thermomechanical properties are specific to each material. Since they are associated with the RVE, they are said to be 'effective' and are determined using models. The resulting modeling is called one-phase modeling.

In the following sections, two classes of simulations are distinguished: simulations based on one-phase modeling and twophase modeling. Background reading for this chapter are books on fluid and solid mechanics (1-4), numerical modeling in materials science and engineering (5-7), and more specific books on semisolid processing: Suery and coauthors' book $(8,9)$, the book edited by Atkinson from the training school organized for the 'THIXOSTEEL' COST 541 consortium on Modeling of SemiSolid Processing (10-13), the overview of achievements of thixoforming edited by Gerhard Hirt and Riener Kopp (14,15), and the book on Semi-Solid Processing of Alloys (16). The literature on numerical models of semisolid processing was reviewed in detail by Atkinson (17).

\section{One-Phase Modeling}

\section{General Equations of the Thermomechanical Problem}

\section{Laws of Conservation}

Equations of conservation can be written for the whole system (the whole semisolid billet) or locally. In the following sections, the equations of conservation are written for a semisolid RVE (blob). In one-phase modeling, the solid fraction of the RVE can change because of solidification/melting phenomena but not because of liquid-solid segregation, which is neglected. In other words, the velocities of the liquid and solid phases are assumed to be equal. Also, the temperatures of the liquid and solid phases are chosen equal. 


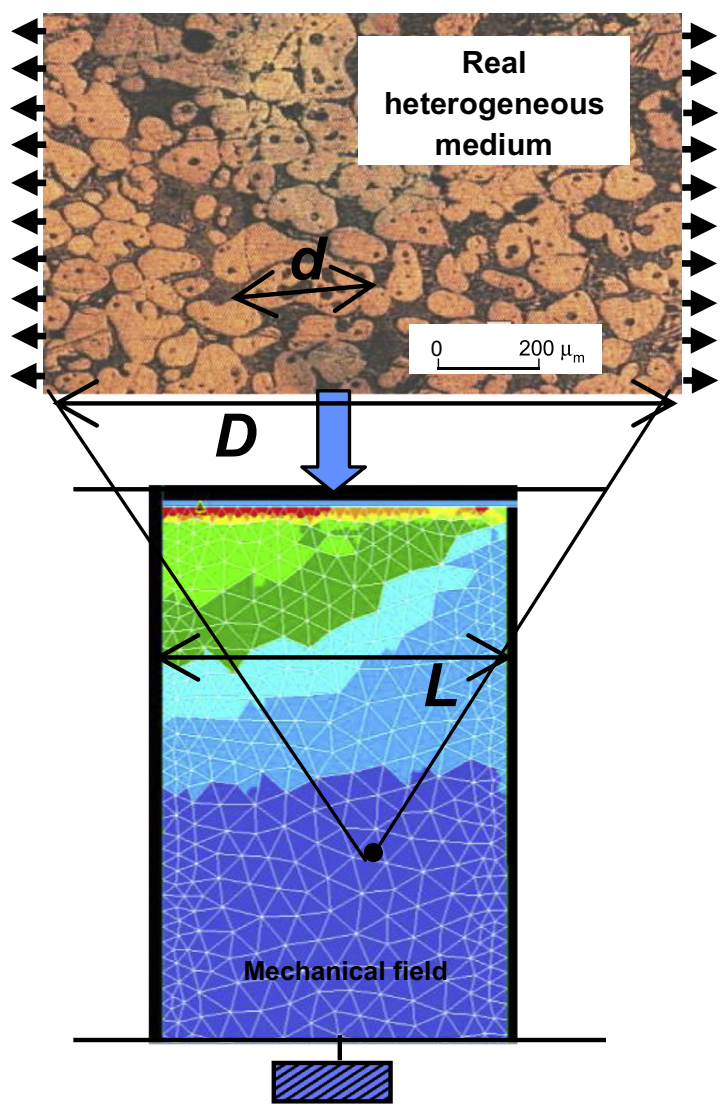

Figure 1 Schematic representation of different scales of analysis (taking here, as an example, a nondendritic semisolid microstructure with globules of solid-appearing pale and liquid between (and within the globules) appearing darker).

\subsection{Mass conservation}

The law of conservation of mass expresses that the time rate of change of density is balanced by a volume change $(\underline{\nabla} \cdot \underline{u})[1]$.

$$
\frac{\mathrm{D}}{\mathrm{D} t} \rho+\rho \underline{\nabla} \cdot \underline{u}=0
$$

\subsection{Solute atom conservation}

As mass, the overall quantity of solute atoms is conserved during processing. The liquid and solid phases have different solute atom concentrations at equilibrium so that solute atoms may diffuse from one phase to another. However, semisolid processing is very rapid, so atom diffusion is usually neglected. The solute atom concentration of RVE is assumed to remain constant over time and is equal to the overall concentration.

\subsection{Momentum conservation}

The law of conservation of momentum states that the time rate of change of momentum (left-hand side) is related to the resultant force acting on the RVE [2]. $\underline{\nabla} \cdot \underline{\underline{\sigma}}$ expresses the internal cohesive forces and $\rho \underline{b}$ the external volume forces such as the gravity forces, which are usually neglected.

$$
\rho \frac{\mathrm{D}}{\mathrm{D} t} \underline{u}=\underline{\nabla} \cdot \underline{\underline{\sigma}}+\rho \underline{b}
$$

For isotropic material such as semisolid alloy, it is convenient to separate the stress tensor $\underline{\underline{\sigma}}$ into its deviatoric $\underline{\underline{S}}$ and hydrostatic parts $-p \underline{\underline{I}}$.

$$
\underline{\underline{\sigma}}=\underline{\underline{S}}-p \underline{\underline{I}}
$$

$p$ is the hydrostatic pressure written as

$$
p=-\frac{1}{3} \operatorname{tr}(\underline{\underline{\sigma}})
$$


Equation [2] can be rewritten as:

$$
\rho \frac{\mathrm{D}}{\mathrm{D} t} \underline{u}=\underline{\nabla} \cdot \underline{\underline{S}}-\underline{\nabla} p+\rho \underline{b}
$$

\subsection{Energy conservation}

The total energy of a system is usually stated as the sum of the internal and kinetic energies. The total energy can change when heat is added to the system and/or work is done by the system. Accounting for the principle of virtual power deduced from the conservation of momentum, the law of conservation of energy, also known as the first law of thermodynamics ([6]), states that the time rate of change of internal energy results, from the left to the right of the right-hand side, from the intrinsic dissipation due to deformation of the continuum, the external volume heat sources (possibly associated with Joule effect or radioactivity but equal to zero in the semisolid processing case), and the heat exchanges (18).

$$
\rho \frac{\mathrm{D}}{\mathrm{D} t} e=\underline{\underline{\sigma}}: \underline{\underline{D}}+r-\nabla \cdot \underline{q}
$$

Phase changes (melting or solidification) may take place during semisolid processing. Some heat, called the latent heat, is released by the material during solidification. As a result, the enthalpy of RVE changes. That is why the enthalpy is preferred to the internal energy to deal with [6]. The enthalpy and internal energy are related via:

$$
h=e+\frac{p}{\rho}
$$

The change of pressure during semisolid processing is small because the solid and liquid are condensed matter and so very little compressible in comparison with gas. So the pressure variation effect on the change of enthalpy is neglected. Taking into account the conservation of mass and eqns [2] and [4] and neglecting external volume heat sources, eqn [6] for semisolid processing can be rewritten as

$$
\rho \frac{\mathrm{D}}{\mathrm{D} t} h=\underline{\underline{S}}: \underline{\underline{D}}-\nabla \cdot \underline{q}
$$

\subsection{Summary}

The thermomechanical problem has 11 unknown variables. They are as follows:

- Three components of the velocity vector from which the six components of the strain rate tensor can be determined by

$$
\underline{\underline{D}}=\frac{1}{2}\left(\underline{\nabla} \underline{u}+\underline{\nabla}^{T} \underline{u}\right)
$$

- Six components of the stress tensor (or equivalently the hydrostatic pressure and the five components of the deviatoric tensor for isotropic material).

- Temperature.

- Density.

Solving differential equations with partial time and spatial derivatives requires specifying initial and boundary conditions of the system. In addition, the number of conservation equations is five (one from [1], three from [2], and one from [8]). Additional relationships between variables are thus needed to solve the problem. Models are proposed to provide these relationships. They can be categorized into relationship between density and temperature, mechanical constitutive equations, and thermal constitutive equations. We mentioned that one-phase modeling ignores the details of the microstructure. However, because the response of the RVE is controlled by the presence of the liquid and solid phases, it is very useful to incorporate internal variables to describe the RVE microstructure on average. Thus, the solid fraction is commonly introduced. Other variables, describing, for instance, the degree of agglomeration of the solid skeleton, may also be used. The current models for semisolid processing simulations are presented in the next sections.

\subsection{Constitutive Equations for Mass Conservation}

Density of metal liquid is about $1-10 \%$ smaller than density of metal solid. As a result, the density of semisolid changes with temperature and solidification/melting phenomenon (not with pressure since solid and liquid are condensed matter). The effective density can be written as a function of temperature or solid volume fraction $f_{\mathrm{s}}$ (or liquid fraction $f_{\mathrm{l}}$ ).

Since,

$$
f_{\mathrm{s}}+f_{\mathrm{l}}=1
$$

one can write:

$$
\rho=f_{\mathrm{s}} \rho_{\mathrm{s}}+\left(1-f_{\mathrm{s}}\right) \rho_{\mathrm{l}}
$$


where $\rho_{\mathrm{s}}$ and $\rho_{\mathrm{l}}$ are the density of the solid phase and liquid phase, respectively. When semisolid solidifies, its density increases since the density of solid in greater than the density of liquid for metal alloys. The conservation of mass [1] requires a volume decrease, leading to the well-known shrinkage phenomenon.

The temperature dependence of $\rho_{\mathrm{s}}$ and $\rho_{\mathrm{l}}$ is usually neglected. Thus, the temperature dependency of RVE is captured via $f_{\mathrm{s}}(T)$ only $f_{\mathrm{s}}(T)$ is thus needed. Since diffusion of solute elements is not taken into account, the solid fraction is assumed to depend on temperature only. For binary alloys, it results in two limit cases: the lever rule model, for which infinite diffusion is considered in the solid and liquid phases, and the Scheil model, for which no diffusion takes place in the solid, while it is still infinite in the liquid (6). Such models can be extended to multicomponent alloys using thermodynamics software (19). Experimental data can also be used. Since the solid fraction-temperature relationship when the semisolid alloy melts or solidifies is not equal and depends on heating/ cooling kinetics (20), it is important but not so simple to get data under the same conditions as processing.

In practice, the density of semisolid is usually assumed to remain constant during processing. The material is said to be incompressible.

\subsection{Constitutive Equation for Momentum Conservation}

The mechanical behavior of semisolid alloy is strongly shear thinning and time dependent (thixotropic). From a modeling point of view, semisolid is commonly considered as an isotropic, incompressible, nonlinear viscous (also called viscoplastic) material. The stress tensor is written as [3] and

$$
\underline{\underline{S}}=2 \eta \underline{\underline{D}}
$$

where $\eta$ is the viscosity. The mathematical representation of viscosity is thus crucial to properly describe the mechanical behavior. Rheological experiments (see Chapter 5.08) showed that viscosity depends on many parameters: solid fraction (temperature), shear rate, and time, but also on the initial degree of agglomeration of solid phase. Different constitutive equations were developed by researchers. They are presented with an increasing degree of sophistication.

\subsection{Constitutive equations for steady-state viscosity}

At isothermal conditions, at the equilibrium state, semisolid alloys are strongly shear thinning (the viscosity decreases with increasing shear rate $\dot{\gamma}$ ), and the most common descriptions are given in Table 1 . The shear rate represents an equivalent strain rate and can be replaced by the von Mises equivalent strain rate $D_{\text {eq }}$

$$
\dot{\gamma}=\sqrt{3} D_{\mathrm{eq}}=\sqrt{2 \underline{\underline{D}}: \underline{\underline{D}}}
$$

The strain rate sensitivity parameter $m$ is equal to 1 for pure liquid (Newtonian behavior) and 0.2-0.3 for pure hot solid (these values are commonly used for hot forging). The consistency $K$ also depends on solid fraction. Some models, inspired from classical suspension rheology modeling $(21,22)$, explicitly incorporated the solid fraction in constitutive equations. For instance, the consistency is assumed to grow exponentially with increasing solid fraction in Joly and Mehrabian's model (23). In practice, $K$ and $m$ are determined for each solid fraction by matching the calculated value to the steady-state experimental viscosity as illustrated in Figure 2.

The Ostwald-de-Waele model reproduces quite well the experimental data in the shear-thinning region but is not sufficient to capture the plateau region found in the case of very high shear rate. This plateau region, associated with a Newtonian behavior, is captured using the Cross model (24). In the case of very low shear rates, the Ostwald-de-Waele predicts an infinite viscosity for $\dot{\gamma}=0$. That is why the Cross model is preferred for industrial applications. However, the Cross model considers that semisolid behaves like a Newtonian fluid, and there is no clear experimental evidence of such behavior: experimental values are sparse and missing (17).

The Herschel-Bulkley model differs from the two others in the yield stress $\tau_{\mathrm{c}}$, which is a property thoroughly discussed in the literature $(14,16,17)$. The yield stress is the stress below which there is no flow of the alloy. It seems that the experimental

Table 1 Main constitutive equations for semisolid alloy considered as suspension

\begin{tabular}{ll}
\hline $\begin{array}{l}\text { Ostwald-de-Waele (also known as power or Norton-Hoff } \\
\text { law in solid mechanics) }\end{array}$ & $\begin{array}{l}\eta=K \dot{\gamma}^{m-1} \\
m: \text { strain rate sensitivity parameter, } \\
\\
\end{array}$ \\
Cross (24) & $\begin{array}{c}\text { pure hot solids, } K: \text { consistency } \\
\end{array}$ \\
& $\frac{\eta-\eta_{\infty}}{\eta_{0}-\eta_{\infty}}=\frac{1}{1+K^{\prime} \dot{\gamma}^{1-m}}$ \\
& $K^{\prime}:$ material parameter \\
& $\eta_{0}, \eta_{\infty}:$ viscosity when $\dot{\gamma} \rightarrow 0, \dot{\gamma} \rightarrow \infty$ \\
& $\dot{\gamma}=0$ for $\tau<\tau_{c} ; \dot{\gamma}=\frac{\tau}{\eta}$ for $\tau \geq \tau_{c}$ with $\eta=\frac{\tau_{c}}{\dot{\gamma}}+K \dot{\gamma}^{m-1}$ \\
Herschel-Bulkley & \\
(Bingham model is obtained for $m=1)$ & $\tau_{c}:$ yield stress
\end{tabular}




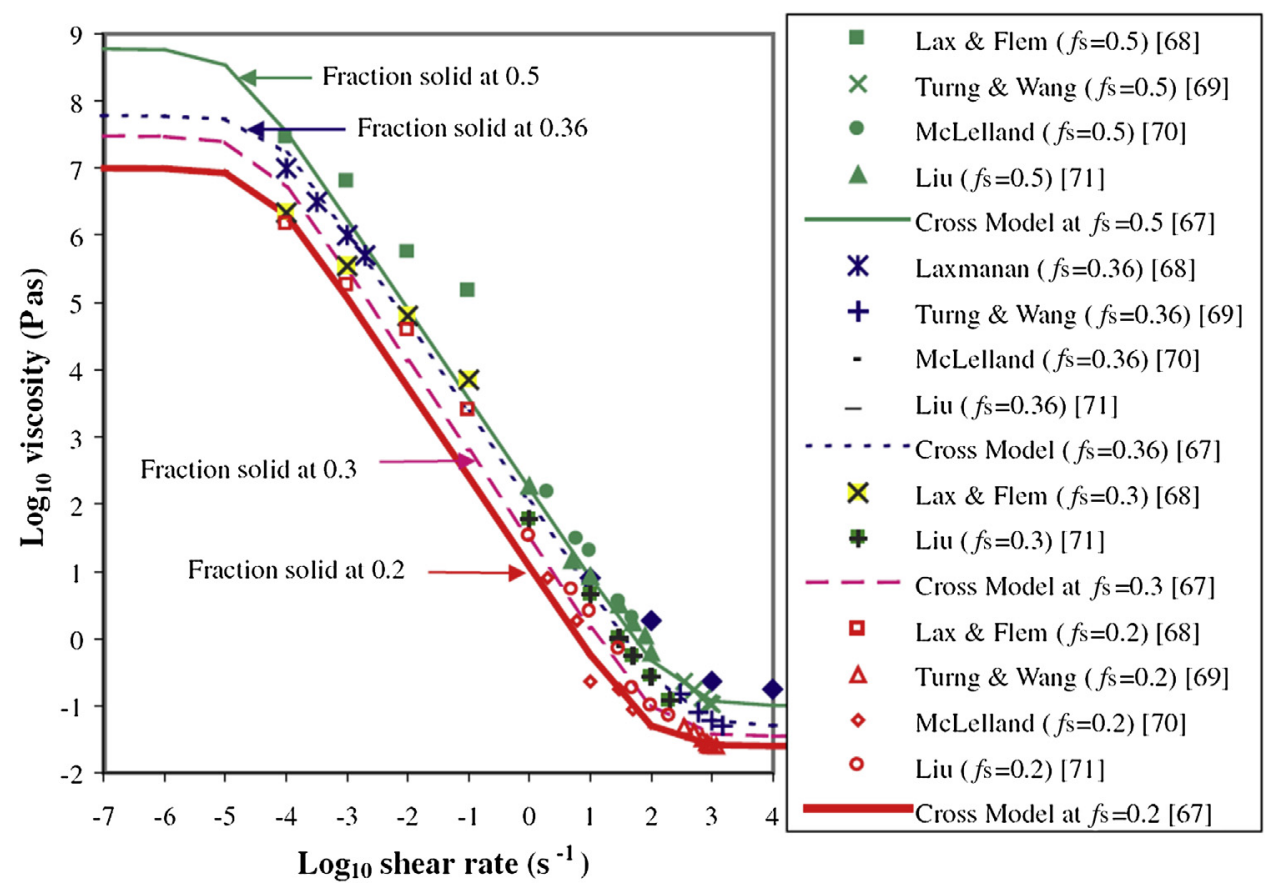

Figure 2 Cross model fitted to apparent viscosities obtained from various works on Sn15\%Pb alloys Reproduced from Atkinson, H. V. Modeling the Semisolid Processing of Metallic Alloys. Prog. Mater. Sci. 2005, 50, 341-412; Liu, T. Y. PhD Thesis, University of Sheffield, Sheffield, UK, 2002.

evidence and the physical justification of such a yield stress are not clear. The main issue is that the yield stress seems more related to transient than steady-state response $(25)$. Modigell and coauthors $(14,26)$ suggested to differentiate between isostructural, dynamic, and static yield stress. Even so, it is very convenient from a computational point of view to include such a yield stress to account for observations of regions described as unyielded or dead in slurry having experienced a forming operation (16).

Most numerical simulations used the constitutive equations discussed because they are simple to implement in numerical code and identify from experiments. However, they describe steady-state response while transient response is involved during semisolid processing. Academic researchers have developed models accounting for the time dependency of semisolid behavior, namely thixotropic behavior.

\subsection{Constitutive equations for thixotropic behavior}

The origin of semisolid thixotropic behavior is now well understood. Solid globules tend to agglomerate at rest and disagglomerate under deformation. Under shear at a given shear rate, the degree of agglomeration of solid phase tends to an equilibrium value resulting from a balance of agglomeration and disagglomeration. A scalar parameter, also labeled as the internal variable or structural parameter, is introduced to describe the degree of agglomeration of the solid globules (approach initially suggested by Cheng and Evans (27) for thixotropic fluids). A fully agglomerated solid phase is usually represented by $\lambda=1$ and a completely disagglomerated solid phase, with all the globules separate from each other, by $\lambda=0$. Thixotropy is introduced mathematically via the time derivative $\mathrm{D} \lambda / \mathrm{D} t=0$. The most general description is given by:

$$
\frac{\mathrm{D}}{\mathrm{D} t} \lambda=a(1-\lambda)^{b}-c \lambda \dot{\gamma}^{d}
$$

The driving force for agglomeration is controlled by the difference of the degree of agglomeration from its maximum value, i.e., $(1-\lambda)$ raised to a power $b$. The rate of disagglomeration is given by the product of the current degree of agglomeration and the shear rate, raised to a power $d$ and, $a$ and $c$ are material constants. At a particular shear rate, the initial degree of agglomeration tends to an equilibrium value given by $\mathrm{D} \lambda / \mathrm{D} t=0$.

The structural parameter was introduced in many constitutive equations. Two examples are given in Table 2 (see also $(28,29)$ and the review (17)). Modigell and coauthors $(14,30)$ proposed to include the structural parameter in the Herschel-Buckley model (Table 2). Brown and coauthors (31-33) suggested a physically based modeling considering that deformation mainly takes place within the solid bonds between the solid globules. Interestingly, Brown and coauthors introduce the concept of effective solid fraction in their modeling. The effective solid fraction $f_{\mathrm{s}}^{\text {eff }}$ accounts for the solid phase and the liquid entrapped inside the solid globules and agglomerates. It is written

$$
f_{\mathrm{s}}^{\mathrm{eff}}=f_{\mathrm{s}}(1+0.1 \lambda)
$$

The entrapped liquid cannot flow and acts as an additional solid phase from a mechanical point of view (34). To better understand the role of this effective solid fraction, Perez et al. (35) simulated the solid cluster formation resulting from competing 


Herschel-Bulkley + thixotropy (30) $\quad \eta=\left[\frac{\tau_{c}}{\dot{\gamma}}+K \dot{\gamma}^{m-1}\right] \lambda$

Brown and coauthors $(31-33)$

$$
\frac{\eta}{\eta_{\mathrm{l}}}=A(\lambda)\left(\frac{\left(f_{\mathrm{s}}^{\mathrm{eff}} / f_{\mathrm{s}}^{\mathrm{c}}\right)^{1 / 3}}{1-\left(f_{\mathrm{s}}^{\mathrm{eff}} / f_{\mathrm{s}}^{\mathrm{c}}\right)^{1 / 3}}\right)+(n+1) C(T) \lambda f_{\mathrm{s}} \eta_{1}^{n} \dot{\gamma}^{n-1}
$$

$\eta_{1:}$ viscosity of liquid, $A(\lambda)$ : hydrodynamic parameter, $C(T)$ : temperature-dependent parameter, $n=1 / \mathrm{m}$ $f_{\mathrm{s}}^{\mathrm{c}}$ : maximum effective volume-packing solid fraction at a given level of agglomeration

kinetics for agglomeration and disagglomeration processes. They calculated the entrapped liquid fraction for different shear rates and clearly observed a relationship between the semisolid viscosity, the effective solid fraction, and the shear rate.

In order to better correlate the role of entrapped and nonentrapped liquid, solid and solid bonds on the mechanical response of semisolid, a model, also called micro-macro model, based on micromechanics and homogenization techniques has been proposed $(36,37)$. The RVE response is deduced from the behavior of the different phases within the material and microstructure. In other words, the material is considered as a multiphase mechanical system for which the momentum equation is solved assuming homogeneous boundary conditions. Because it is impossible to have knowledge on every detail of the microstructure, only relevant statistical information for the microstructure is incorporated in the definition of RVE. Semisolid is a two-physical phase system. However, from a mechanical point of view, four mechanical phases can be differentiated: the solid globules, the solid bonds between the solid spheroids, the entrapped liquid, and the nonentrapped liquid (Figures 3 and 4(a)). As mentioned previously, the viscoplastic deformation is mainly concentrated in the solid bonds and the free liquid carries the flow. In contrast, the solid globules entrapping some liquid deform very little, though they strongly contribute to increase the semisolid resistance because of hydrodynamic interactions among agglomerates. In a statistical representation of the microstructure, this complex system is viewed as a spherical 'inclusion' (because of the isotropic spatial distribution of heterogeneities) gathering all the solid globules with entrapped liquid surrounded by a shell (coating) composed of the solid bonds and the free liquid (Figures 4(b) and 4(c)). This representation is used to emphasize the spatial distribution of solid and liquid and to concentrate the deformation in the solid bonds and the free liquid. As a consequence, the shell is called the active zone from the deformation point of view. The mechanical response of such representation is calculated by solving the momentum conservation equation. A constitutive equation given for each phase is required. The solid phases are taken as pure nonlinear incompressible viscous material. The liquid phases are considered as Newtonian fluid.

The solid fraction in the active zone, which represents the quantity of solid bonds, is taken as structural parameter. Its time derivative is chosen similar to $\mathrm{D} \lambda / \mathrm{D} t=0$ except that it also depends on solid fraction. This dependence offers the possibility to include the pure liquid or solid case.

\subsection{How to describe the transition from liquidlike to solidlike behavior?}

The main challenge of thixotropic modeling is actually to capture the transition from a solidlike behavior when the solid globules form a solid skeleton $(\lambda=1)$ to a liquidlike behavior when the globules are separated from each other $(\lambda=0)$. Historically, constitutive equations developed to describe semisolid behavior resulted from the theory of suspension considered as pure viscous fluid. In general, solid displays elastic-viscoplastic behavior. Viscoplasticity takes place when the solid is subjected to higher stresses than its yield stress. Solid usually hardens with plastic deformation. At temperatures close to solidus, the yield stress and hardening (which decrease with increasing temperature) are negligible. The solid becomes a pure viscoplastic material and its behavior is commonly described by the Ostwald-de-Waele law, which is called the power or Norton-Hoff law in solid mechanics. So, in this case (which is the case of semisolid alloy), the solid and liquid approaches join one from each other. In practice, as with yield stress, it is very useful to introduce an elastic-type behavior to describe the semisolid response in the first stage of the deformation. Figure 5 shows that compression tests (39) exhibit a steep rise of load up to a peak at the beginning of the test. It has been demonstrated that a pure viscous formalism cannot reproduce such a behavior (37). Additionally, incorporating elasticity offers the possibility to

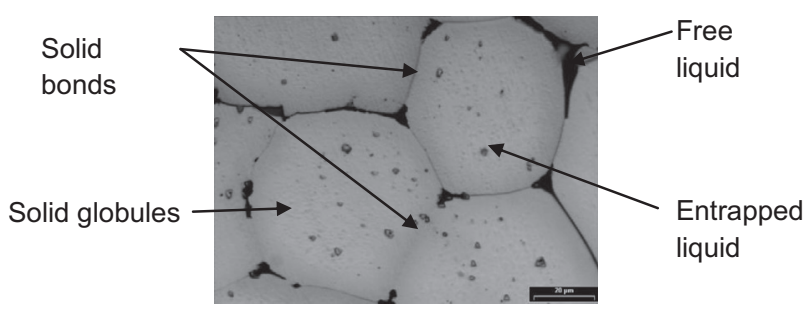

Figure 3 Microstructure of 7075 alloy after water quenching from the semisolid state with 0.82 solid fraction. Reproduced from Neag, A.; Favier, V.; Bigot, R.; Pop, M. Microstructure and Flow Behavior during Backward Extrusion of Semi-Solid 7075 Aluminium Alloy. J. Mater. Process. Technol.

2012, 212, 1472-1480. 
(a)

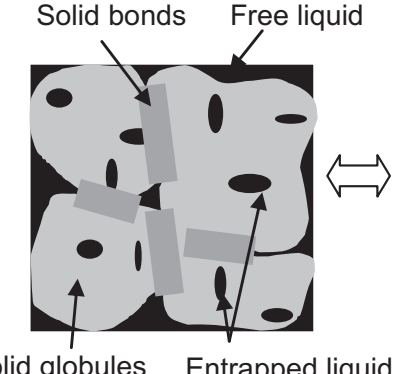

(c)

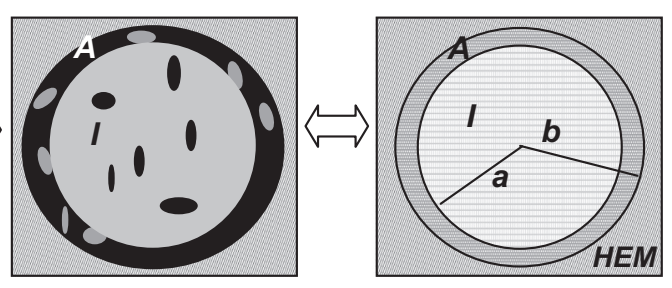

Figure 4 (a) Schematic representation of the semisolid microstructure. (b) Representation of the four mechanical phases distributed in one inclusion of solid containing entrapped liquid surrounded by a shell of free liquid and solid bonds. (c) Homogenization procedure: the coated inclusion is embedded into a matrix representing the homogeneous equivalent medium having the effective properties of the real heterogeneous semisolid material. Reproduced from Favier, V.; Cezard, P.; Bigot, R. Transient and Non-Isothermal Semi-Solid Behaviour: 3D Micromechanical Modeling. Mater. Sci. Eng. A 2009, 517, 8-16.

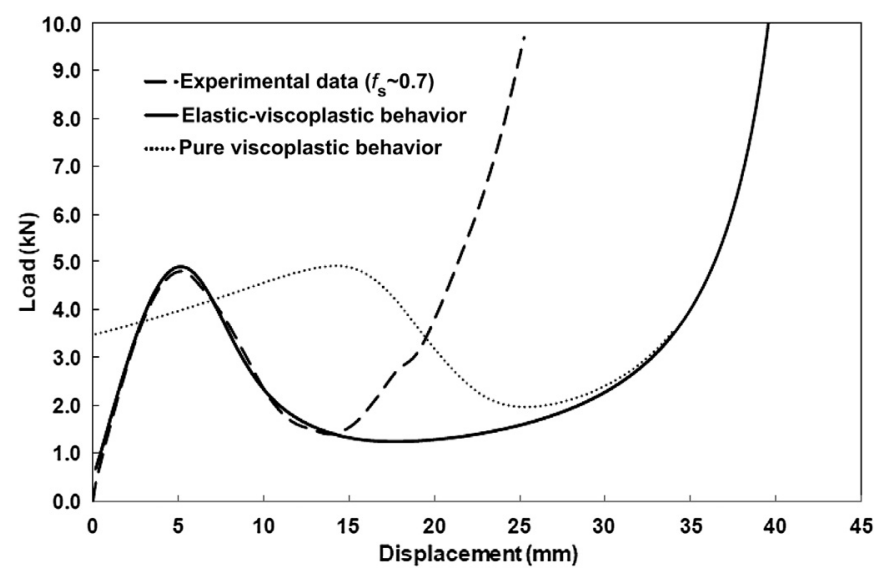

Figure 5 Experimental and predicted load-displacement curves comparing an elastic-viscoplastic model, a pure viscoplastic model (both with fraction solid of 0.7) (Reproduced from Favier, V.; Atkinson, H. V. Micromechanical Modelling of the Elastic-Viscoplastic Response of Metallic Alloys under Rapid Compression in the Semi-Solid State. Acta Mater. 2011, 59, 1271-1280.), and experimental results (Reproduced from Liu, T. Y.; Atkinson, H. V.; Kapranos, P.; Kirkwood, D. H.; Hogg, S. C. Rapid compression of aluminum alloys and its relationship to thixoformability. Metallurgical Transactions, $A$ 2003, 34, 1545-1554.) for Alusuisse A356 alloy at $574{ }^{\circ} \mathrm{C}$ and a ram speed of $500 \mathrm{~mm} \mathrm{~s}^{-1}$.

investigate residual stresses after unloading and cooling down to room temperature. A complete model that captures the thixotropic and temperature-dependent behavior and can degenerate properly to pure solid or liquid behavior as well as free solid suspensions was proposed (40). However, it has to cope with the issue of model parameter identification.

\subsection{Constitutive Equations for Energy Conservation}

As mentioned, density and viscosity strongly depend on temperature and solid fraction. The temperature field is given by the equation of conservation of energy [8]. The internal heat source term comes from intrinsic dissipation. It is calculated from constitutive equations mentioned (Section 5.10.3.1.3):

$$
\underline{\underline{S}}: \underline{\underline{D}}=2 \eta \underline{\underline{D}}: \underline{\underline{D}}=3 \eta D_{\text {eq }}^{2}
$$

The heat flux vector is given by the isotropic Fourier law:

$$
\underline{q}=-k \underline{\nabla} T
$$

where $k$ is the effective thermal conductivity of semisolid RVE. Conductivity for solid phase is greater than for liquid phase. The effective conductivity is commonly estimated by using a mixture law:

$$
k=f_{\mathrm{s}} k_{\mathrm{s}}+\left(1-f_{\mathrm{s}}\right) k_{\mathrm{l}}
$$

It may also depend on the connectivity of the solid phase, but this phenomenon is neglected. As far as Dh/Dt is concerned, additional relationships between enthalpy, solid fraction, and/or temperature are required. When no phase change is involved, for condensed matter such as semisolids, the specific enthalpy is given by:

$$
h(\underline{x}, t)=\int_{0}^{T(\underline{x}, t)} c_{\mathrm{p}}\left(T^{\prime}\right) \mathrm{d} T^{\prime}
$$


where $c_{\mathrm{p}}(T)$ is the specific heat for constant pressure. Note that $c_{\mathrm{p}}$ depends on temperature only (and not directly on time and space). In this case, the equation of energy conservation becomes a simple balance heat equation:

$$
\rho c_{\mathrm{p}} \frac{\mathrm{D} T}{\mathrm{D} t}=\underline{\nabla} \cdot(k \nabla T)+\underline{\underline{S}}: \underline{\underline{D}}
$$

When phase change is involved, enthalpy-temperature curves exhibit a steep rise corresponding to the latent heat of fusion (Figure 9). In one-phase modeling, an additional internal heat source is introduced and the conservation of energy is written:

$$
\rho c_{\mathrm{p}} \frac{\mathrm{D}}{\mathrm{D} t} T=\underline{\nabla} \cdot(k \nabla T)+\underline{\underline{S}}: \underline{\underline{D}}+\rho L^{(\mathrm{s} / \mathrm{l})} \frac{\mathrm{D}}{\mathrm{D} t} f_{\mathrm{s}}
$$

As $k, c_{\mathrm{p}}$ is the effective specific heat calculated, commonly given by a mixture law:

$$
c_{\mathrm{p}}=f_{\mathrm{s}} c_{\mathrm{ps}}+\left(1-f_{\mathrm{s}}\right) c_{\mathrm{pl}}
$$

$L^{(\mathrm{s} / 1)}$ is the latent heat of fusion. If a relationship between the solid fraction and temperature is specified (typically the Scheil or lever rule models), $\frac{\mathrm{D}}{\mathrm{D} t} f_{\mathrm{s}}$ is calculated via the relation $\frac{\mathrm{D}}{\mathrm{D} t} f_{\mathrm{s}}=\frac{\mathrm{d} f_{\mathrm{s}}}{\mathrm{d} T} \frac{\mathrm{D}}{\mathrm{D} t} T$ so that [21] is transformed to:

$$
\rho c_{\mathrm{EQ}} \frac{\mathrm{D}}{\mathrm{D} t} T=\underline{\nabla} \cdot(k \nabla T)+\underline{\underline{S}}: \underline{\underline{D}}
$$

with

$$
c_{\mathrm{EQ}}=c_{\mathrm{P}}-L^{(\mathrm{s} / \mathrm{l})} \frac{\mathrm{d} f_{\mathrm{s}}}{\mathrm{d} T}
$$

This method is called the equivalent specific heat coefficient method.

\subsection{Boundary and Initial Conditions}

\subsection{Initial conditions}

Semisolid processing is very rapid, involving many and strong changes in velocity, pressure, and temperature fields as well as microstructure. It is labeled as an unsteady-state problem (it involves transient regimes). Numerical simulations require specifying the starting state of the billet and dies. A simple but not so realistic approach is to consider a uniform initial state; namely, velocity and temperature fields are the same in the whole billet. Initial temperature is assumed to be the target temperature of the billet. Initial velocities are taken equal to zero. For CFD code, the initial pressure is taken equal to the atmospheric pressure. For solid mechanics-based code, the residual stresses are taken equal to zero.

The hypothesis of uniform initial state is right when the semisolid is obtained from the liquid state. When the billet is reheated from the solid state in an induction furnace, heat losses caused by convection and radiation at the lateral surface of the slug and by heat conduction at the surface bottom occur. Consequently, a large difference between the core and the edge temperature exists $(41,42)$. The transportation of the billet from the reheating to processing place involves also some temperature gradients (43).

\subsection{Boundary conditions}

Industrial thixoformed or rheoformed components have complex 3D shapes. The 3D numerical simulations are required to simulate their processing and the boundary conditions are set at the billet boundaries. In the case of components having symmetry that is conserved during processing such as axisymmetric cups or wheels, $2 \mathrm{D}$ simulation can be used and specific boundary conditions apply on axis symmetry (6).

\subsection{1 Thermal boundary conditions}

Thermal exchanges at the billet surface (air/billet or die/billet) are usually represented by:

$$
\underline{q} \cdot \underline{n}=h_{\text {ext }}\left(T-T_{\text {ext }}\right)
$$

$h_{\text {ext }}$ is the heat transfer coefficient. It relates the heat flux density to the temperature difference between the billet and the environment, commonly chosen as room or die temperature. $h_{\text {ext }}$ takes into account the overall heat exchanges: conduction, convection, and radiation. It changes during the processing due to solidification, change in semisolid viscosity, and contact area between the die and the billet. Knowledge of $h_{\text {ext }}$ is still a big challenge. It is usually estimated using an inverse method $(6,42)$. Thermocouples are fixed in the tool and possibly in the billet $(42,44)$. The experimental temperature values are compared with simulated curves considering the tool as thermoelastic to determine the heat transfer between forming material and tool. In practice and for industrial applications, the tools are considered as rigid bodies because the computational time is about 10 times longer with thermoelastic than rigid tools. Since the definition of rigid dies has an influence on the heat flow compared with the experimental values, the heat transfer coefficient has to be readjusted (42).

In the solid mechanics approach, heat due to friction at the die wall/billet is accounted for using thermal boundary conditions, while in CFD it is incorporated in the internal heat source term via [16]. In the solid mechanics formalism, it is calculated by the 

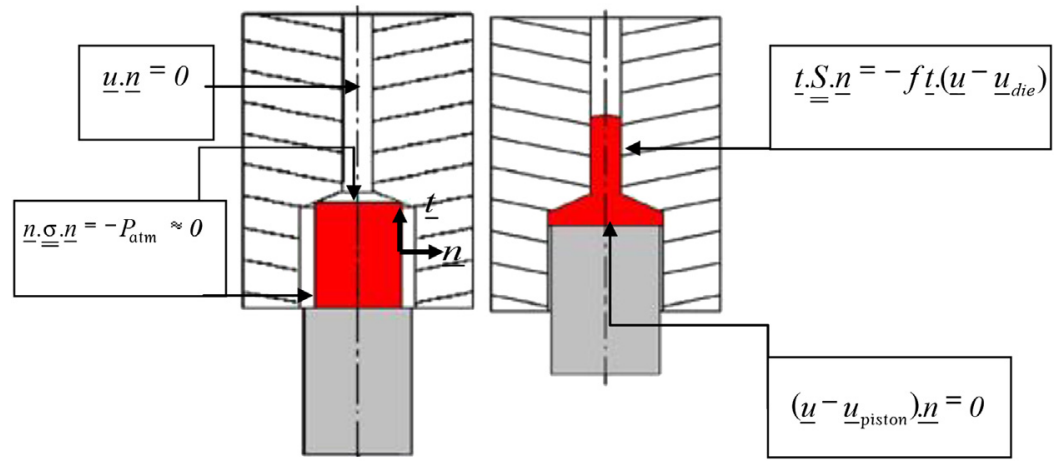

Figure 6 Schematic representation of a thixoextrusion test at two instants in time studied in Becker et al. (Becker, E.; Favier, V.; Bigot, R.; Cézard, P.; Langlois, L. Impact of Experimental Conditions on Material Response during Forming of Steel in Semi-Solid State. J. Mater. Process. Technol. 2010, 210, 1482-1492; Becker, E.; Bigot, R.; Langlois, L. Thermal Exchange Effects on Steel Thixoforming Processes. Int. J. Adv. Manuf. Technol. 2010, 48, 913-924.). Illustration of mechanical boundary conditions.

product of the tangential stress at the wall/billet interface and the tangential component of the difference between the material and tool velocity vector.

$$
\underline{q} \cdot \underline{n}=(\underline{t} \cdot \underline{\underline{S}} \cdot \underline{n}) \times\left(\underline{t} \cdot\left(\underline{u}-\underline{u}_{\mathrm{tool}}\right)\right)
$$

Expressions of quantities involving in [26] are given by [30] and [31].

\subsection{2 Mechanical boundary conditions}

Figure 6 shows the principle of a thixoextrusion test studied by Becker et al. (43) at two instants in time. The die was axisymmetric, so a 2D axisymmetric simulation is appropriate. This example is used to illustrate the various types of mechanical boundary conditions that are commonly implemented in numerical simulation of semisolid processing. In general, a stress (or pressure) or velocity vector can be applied at the billet boundaries. To simulate the effect of gas pressure $P_{\text {gas }}$ in the dies, the boundary condition is:

$$
\underline{n} \cdot \underline{\sigma} \cdot \underline{n}=-P_{\text {gas }}
$$

where $\underline{n}$ is the unit normal vector at the gas/billet interface. In Figure 6 , the gas pressure is equal to the atmospheric pressure. For billet surface in contact with a moving tool such as the piston, the normal velocity of the tool and billet at the interface is assumed equal.

$$
\left(\underline{u}-\underline{u}_{\text {tool }}\right) \cdot \underline{n}=0
$$

What about the tangential velocity? When fluid mechanics is used two limit cases can be differentiated: no-slip condition (perfect adhesion)

$$
\underline{u}=\underline{u}_{\text {tool }}
$$

and slip condition

$$
\underline{t} \cdot \underline{\underline{S}} \cdot \underline{n}=-f \underline{t} \cdot\left(\underline{u}-\underline{u}_{\text {tool }}\right)
$$

where $f$ is a friction coefficient. Its determination is very difficult since it depends on many parameters such as surface roughness, temperature, contact pressure, and so on $f=0$ expresses a perfect slip (perfect lubrification). Wall slip effects can take place in semisolid processing related to the presence of a thin film of liquid at the wall/billet interface $(45,46)$. These effects are very difficult to model. Similar laws are used in the solid mechanics approach. In addition, the role of contact pressure is explicitly taken into account via the modified friction Coulomb's law:

$$
\begin{gathered}
\underline{t} \cdot \underline{\underline{S}} \cdot \underline{n}=f \underline{n} \cdot \underline{\underline{\sigma}} \cdot \underline{n} \text { for } f \underline{n} \cdot \underline{\sigma} \cdot \underline{n} \leq \tau_{\max } \\
\underline{t} \cdot \underline{\underline{S}} \cdot \underline{n}=\tau_{\max } \text { others }
\end{gathered}
$$

Finally, for 2D axisymmetric numerical simulations, the boundary conditions at the axisymmetric axis are:

$$
\underline{u} \cdot \underline{n}=0
$$

\subsubsection{Simulation and Validation}

Semisolid shows time, strain-rate, and temperature-dependent response during processing. Large deformation, solidification/ melting, and coupled thermomechanics phenomena take place. Commercial software currently used to deal with semisolid processing can be classified using three main criteria:

- The solid or fluid approach to represent material constitutive equations and momentum conservation equation. 
- The method to follow the flow: the Lagrangian or Eulerian representation. Currently mixed Lagrangian and Eulerian approaches are being developed.

- The discretization method used to approximate the set of the differential equations of the system: finite differences, volume differences, and finite elements.

Models and software based on solid body mechanics result from generic software or more specific codes dedicated to solid forming processes. They use the finite element method and the Lagrangian representation. The mesh used to spatially discretize the system is attached to material volume elements (or RVE). It is strongly distorted because of the large deformation involved resulting in strong calculation errors. This drawback is partly coped with using arbitrary Lagrangian-Eulerian (ALE) representation, which often needs to be complemented by a remeshing method, which is computationally time consuming. The main advantage of these models comes from the fact the thermomechanical history of the RVE is followed over the processing time and residual stresses can be estimated. Thus, transient response that is dominant for semisolid processing is straightforward to analyze. In addition, the knowledge of the final state of the component can be very useful to predict the in-life response of the component and optimize the processing routes with respect to final target properties $(5,7)$.

Models and software based on CFD result from generic software or more specific codes dedicated to liquid casting or foundry. They use the finite volume or difference method and the Eulerian representation. The mesh used to spatially discretize the system is attached to space volume elements. It is fixed in space. Mesh distortions are thus avoided and the flow behavior is much easier to obtain than using the Lagrangian representation. However, the knowledge of the thermomechanical history of RVE is not straightforward and free surfaces are not described. This drawback is partly solved using an appropriate strategy for the tracking of the material-air interfaces (47).

Comparisons between experiments and simulations are very useful to assess the reliability of the modeling and to improve the understanding of the processing. In situ visualization of the semisolid flow during processing is complex since the dies are closed and opaque. The main recent work with transparent glass sided dies to film die filling is that by Ward et al. (48) and Hufschmidt et al. (49). These two examples are selected to illustrate numerical simulations of semisolid processing and comparisons with experiments. Hufschmidt et al.'s works are presented in the next section dedicated to two-phase modeling. Figure 7 shows a 3D view of the filling system similar to the one used in Ward et al. experiments (50). The billet is first pushed into a vertical die, compressed by the upper part of the die, and then turns $90^{\circ}$ to enter into a $60 \mathrm{~mm}$ square plate $7.5 \mathrm{~mm}$ thick, tapered to triangular overflow. An obstacle was placed symmetrically in the die. Experiments were conducted on isothermal conditions. The material under study is an A357 aluminum alloy with a solid fraction of about 0.5 .

Numerical simulations were performed with the solid mechanics-based software FORGE2009@. The Lagrangian representation and the finite element method with remeshing were used. The thixoextrusion test displays a symmetric surface so that the half of the
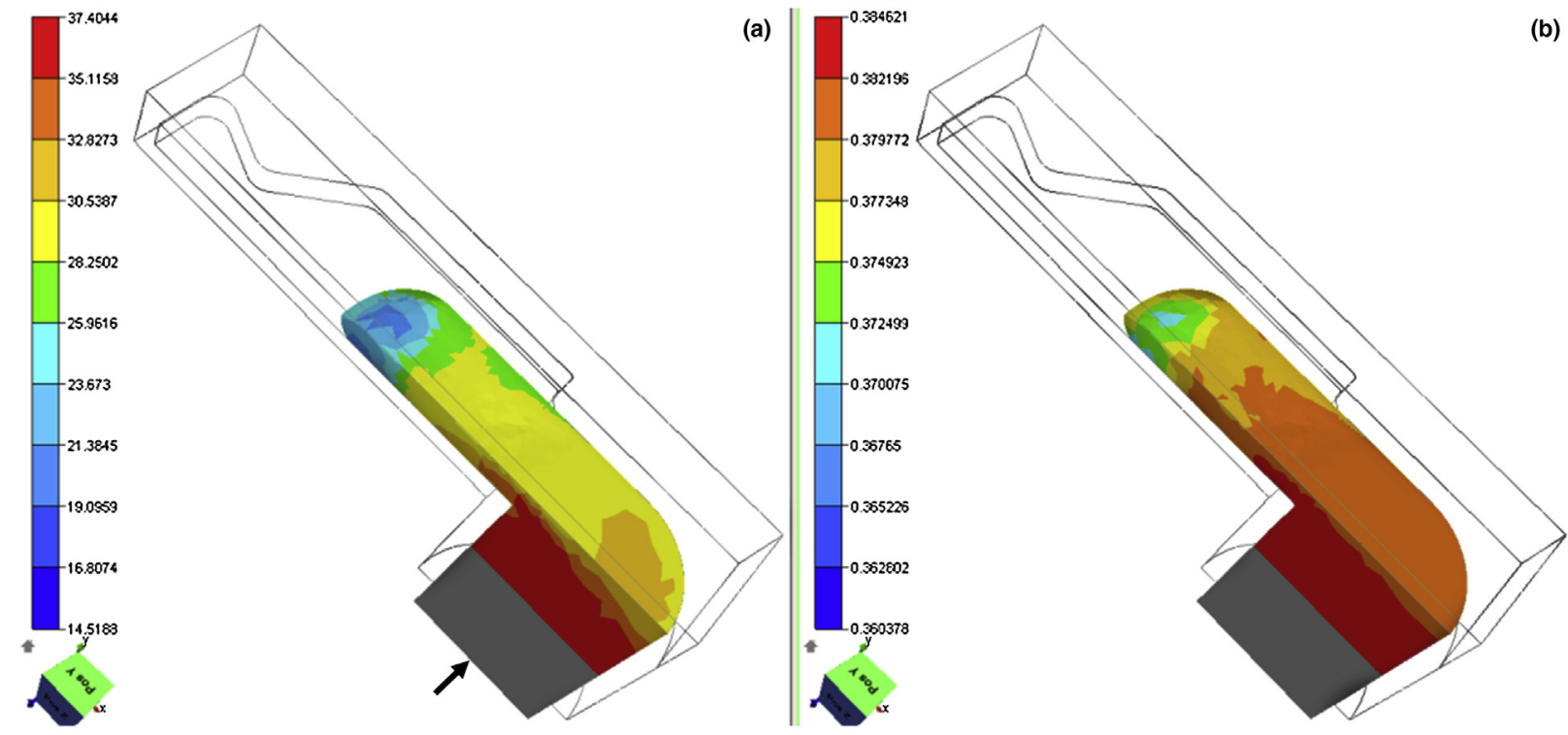

The arrow represents the vertical axis

Figure 7 Numerical simulation of the experiments of Ward et al. (Wang, P. J.; Atkinson, H. V.; Kirkwood, D. H.; Chin, S. B. Final Report for Engineering and Physical Sciences Research Council Project 'Modeling Thixotropic Flow of Metal Alloys into a Die' (GR/M17334/01), 2002) http://www.le.ac.uk/engineering/ staff/atkinson_files/modeling_final_report.pdf)). The filling test has a $90^{\circ}$ flow path change. (a) viscosity (Pa.s); (b) solid fraction in the active zone, which describes the quantity of solid bonds in the micro-macro model (Reproduced from Favier, V.; Cezard, P.; Bigot, R. Transient and Non-Isothermal Semi-Solid Behaviour: 3D Micromechanical Modeling. Mater. Sci. Eng. A 2009, 517, 8-16; Favier, V.; Atkinson, H. V. Micromechanical Modelling of the Elastic-Viscoplastic Response of Metallic Alloys under Rapid Compression in the Semi-Solid State. Acta Mater. 2011, 59, 1271-1280.). The blue and red colors are associated with the smallest and greatest values, respectively. Courtesy: Neag, A. "Simulation of Filling Test with $90^{\circ}$ Flow Path Change." Private Communication, 2012. 


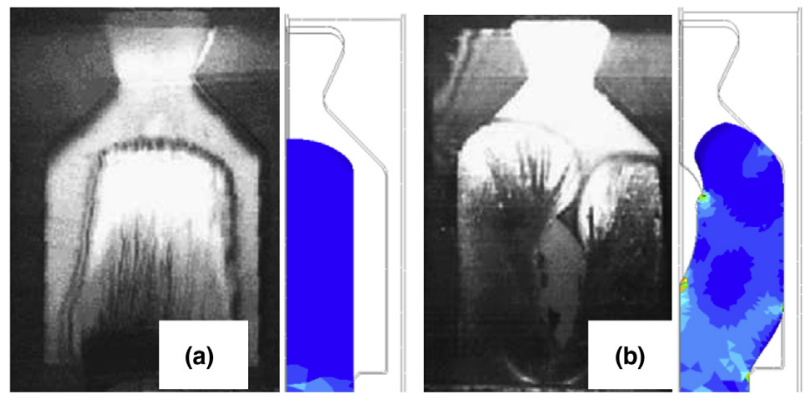

Figure 8 Comparison of experimental and predicted flow front without (a) and with (b) obstacle. Simulations show the von Mises equivalent strain rate [12]. Courtesy: Ward, P. J.; Atkinson, H. V.; Kirkwood, D. H.; Chin, S. B. Final Report for Engineering and Physical Sciences Research Council Project 'Modeling Thixotropic Flow of Metal Alloys into a Die' (GR/M17334/01), 2002, http://www.le.ac.uk/engineering/staff/atkinson_files/modeling_final_report.pdf and Neag, A. "Simulation of Filling Test with 90 Flow Path Change." Private Communication, 2012.

system was modeled. Consistently with experiments, isothermal simulations were carried out. The piston (in gray in Figure 7) is considered as a rigid body and moves with a constant speed of $250 \mathrm{~mm} \mathrm{~s}^{-1}$. The boundary condition at the piston-billet interface is described by [30]. The glass die sides are represented by rigid tools. The friction between the glass die and semisolid is considered very small. It is represented by the modified friction Coulomb's law with $f=0.075$ [31]. The boundary condition at the air-billet interface is described by [27] with $P=0 \mathrm{MPa}$. The semisolid is considered as incompressible and its viscosity is described by the micro-macro model (see Section 5.10.3.1.3.2). The solid fraction is 0.5. Parameters of the constitutive models were identified on the load-displacement curves obtained for rapid compression tests (39).

The predicted viscosity was found to strongly decrease at the entrance of the horizontal plate (Figure 7(a)). This steep decrease is related to the breakdown of the solid agglomerates because of strong shear within solid bonds (the quantity of solid bonds is represented by the solid fraction in the active zone). Figure 8 compares the experimental and calculated flow front without (a) and with (b) obstacle. In the horizontal plate, the flow is parallel, resulting in insufficient spreading of the slurry to fill the 'shoulders' before the slurry had reached the end of the die. The presence of an obstacle improved the filling pattern as the slurry was pushed into the shoulders. Calculated results capture quite well the observed phenomena.

\subsubsection{Conclusion for One-Phase Modeling}

The previous example pointed out that one-phase modeling is able to predict die filling behavior in terms of flow front in a reasonable range. As a result, it is of great interest to optimize die geometry: adding an obstacle improves the filling in the shoulders in the previous example. However, it cannot express liquid-solid segregation that may take place under some processing conditions. As a result, an obvious drawback of one-phase modeling is that it cannot help you avoid these phenomena! More complex modeling incorporating the different response of the liquid and solid phase in the equations of conservation and the couplings between them is required. Basic concepts of such modeling, the so-called two-phase modeling, are presented in the next section.

\subsubsection{Two-Phase Modeling}

Semisolid alloy is considered as a solid skeleton saturated with liquid. There are two mechanisms responsible for liquid-solid segregation: the pressure gradient and the compressibility of the porous solid phase (11). In the following, we explain how two-phase modeling captures these phenomena. Two-phase models for semisolids are inspired from mechanics of saturated porous media (51).

\subsubsection{General Equations of the Thermomechanical Problem}

\subsection{Laws of Conservation}

Two-phase modeling results from the multiphase continuum theory (52-55). The RVE is viewed as the superposition of two continuum media, the solid and liquid phases, and is characterized by solid fraction. Conservation equations are written and provide density, velocity, and pressure (stress tensor) for each phase. The effective RVE response results from the response of the liquid and solid phase and also interactions between the two phases. Consequently, conservation equations are similar to those in classical continuum mechanics (eqns [1],[5], and [8]) but have an additional term to take into account these interactions. Solving the complete problem is complex. In the following, conservation equations and constitutive models commonly used for semisolid processing numerical simulations are presented. Contrary to the micromechanical model, the RVE and liquid and solid phase constitutive models are not deduced from the solid and liquid intrinsic constitutive models and so specific models for solid and liquid phases and RVE are required. It is more convenient to write conservation equations for the RVE and liquid phase instead of solid and liquid phases. The transition from RVE to solid equation is easily obtained by an averaging procedure applied on field variables (density, velocity vector, temperature, etc.). 
5.10.4.1.1.1 Mass conservation

The conservation of mass for the RVE is written as [1]:

$$
\frac{\mathrm{D}}{\mathrm{D} t} \rho+\rho \underline{\nabla} \cdot \underline{u}=0
$$

$\rho$ is given by $[11]$ and $\underline{u}$ is written as:

$$
\underline{u}=f_{\mathrm{s}} \underline{u}_{\mathrm{s}}+\left(1-f_{\mathrm{s}}\right) \underline{u}_{\mathrm{I}}
$$

The intrinsic densities of the liquid $\rho_{\mathrm{l}}$ and solid $\rho_{\mathrm{s}}$ phases are assumed to remain constant over time. However, the density of the liquid phase over the RVE $\left(1-f_{s}\right) \rho_{\mathrm{I}}$ may change because of volume change of the liquid phase and source/sink of liquid due to melting/solidification phenomena. The conservation of mass for the liquid phase within the RVE is written as:

$$
-\rho_{\mathrm{l}} \frac{\mathrm{D}}{\mathrm{D} t} f_{\mathrm{s}}+\left(1-f_{\mathrm{s}}\right) \rho_{\mathrm{l}} \underline{\nabla} \cdot \underline{u}_{\mathrm{l}}=\rho_{\mathrm{l}}^{\text {source }}
$$

$\rho_{1}^{\text {source }}$ can be calculated by the Scheil or lever rule model as in (56) or taking into account the nature of liquid-solid interface $(6)$ :

$$
\rho_{\mathrm{l}}^{\text {source }}=-\rho_{\mathrm{l}} \frac{\mathrm{d} f_{\mathrm{s}}}{\mathrm{d} T} \frac{\mathrm{D}}{\mathrm{D} t} T
$$

Equation [35] is rewritten as:

$$
\frac{\mathrm{D}}{\mathrm{D} t} f_{\mathrm{s}}-\left(1-f_{\mathrm{s}}\right) \underline{\nabla} \cdot \underline{u}_{\mathrm{l}}=\frac{\mathrm{d} f_{\mathrm{s}}}{\mathrm{d} T} \frac{\mathrm{D}}{\mathrm{D} t} T
$$

\subsection{Momentum conservation}

The conservation of momentum for the RVE is written as (gravity forces are neglected for the sake of writing simplicity):

$$
\rho \frac{\mathrm{D}}{\mathrm{D} t} \underline{u}=\underline{\nabla} \cdot \underline{\underline{S}}-\underline{\nabla} p
$$

The RVE is commonly assumed to exhibit an isotropic incompressible nonlinear viscous behavior. Its constitutive equation is represented by [3] and [12].

$$
\begin{gathered}
\underline{\underline{\sigma}}=\underline{\underline{S}}-p \underline{\underline{I}} \\
\underline{\underline{S}}=2 \eta \underline{\underline{D}}
\end{gathered}
$$

As for liquid-saturated porous media treated in soil mechanics (57), the pressure $p$ in the RVE (and solid phase) results from the liquid pressure due to the compression of the porous skeleton (interstitial pressure). The effective viscosity can be described via the various models explained in Section 5.10.3.1.3.

The intrinsic behavior of liquid is considered as Newtonian, characterized via [12] with a constant viscosity $\eta_{1}$. The behavior of the liquid phase in the RVE is given by the intrinsic liquid behavior weighted by the liquid fraction:

$$
\underline{\underline{S}}_{1}^{\text {over RVE }}=\left(1-f_{\mathrm{s}}\right) \underline{\underline{S}}_{1}=\left(1-f_{\mathrm{s}}\right) 2 \eta_{1} \underline{\underline{D}}_{1}
$$

The momentum conservation of the liquid phase in the RVE may change because of internal cohesive forces within the liquid and volume forces coming from the solid $M^{\text {source, }}$

$$
\rho_{l} \frac{\mathrm{D}}{\mathrm{D} t}\left(1-f_{\mathrm{s}}\right) \underline{u}_{\mathrm{l}}=\underline{\nabla} \cdot\left(1-f_{\mathrm{s}}\right) \underline{\underline{S}}_{1}-\left(1-f_{\mathrm{s}}\right) \underline{\nabla} p+M^{\text {source }}
$$

$M^{\text {source }}$ can be viewed as a specific interface friction force proportional to the slip velocity difference:

$$
M^{\text {source }}=\frac{\left(1-f_{\mathrm{s}}\right)}{f_{\mathrm{s}}} \frac{\eta_{\mathrm{l}}}{K_{\mathrm{s}}}\left(\underline{u}-\underline{u}_{\mathrm{l}}\right)
$$

For high solid fractions, the momentum conservation equation of the liquid phase reduces to Darcy's law:

$$
\left(\underline{u}_{\mathrm{s}}-\underline{u}_{\mathrm{l}}\right)=\frac{K_{\mathrm{s}}}{\eta_{\mathrm{l}}} \underline{\nabla} p \Leftrightarrow\left(\underline{u}-\underline{u}_{\mathrm{l}}\right)=\frac{K_{\mathrm{s}}}{f_{\mathrm{s}} \eta_{\mathrm{l}}} \underline{\nabla} p
$$

$K_{\mathrm{s}}$ is the permeability of the solid phase, which depends on fraction and morphology of the solid phase $(9,56)$.

The earliest two-phase models assumed that the liquid acted only via the interstitial pressure and its viscosity was neglected $(58,59)$. Later, models taking into account the viscous flow resistance of the liquid were developed $(14,49,56,60)$ as expressed in [40]. Instead of postulating the RVE constitutive equation, the solid phase behavior can be modeled. The intrinsic solid behavior is assumed as incompressible nonlinear viscous, but the porous solid phase is viewed as a nonlinear viscous compressible medium. Its constitutive equation relates an equivalent strain rate to an equivalent stress that depends on the first two invariants of the stress 
tensor to incorporate pressure effects (61). A parameter (which may be related to the degree of cohesion of the solid phase) is introduced (62-64). These models provide a not-symmetric behavior under tension and compression as shown experimentally (see Chapter 5.08).

\subsection{Energy conservation}

Solving the complete thermal problem is complex. To simplify it, temperatures in the solid and liquid phases are assumed equal. This hypothesis is justified because the heat transfer at the solid-liquid interface is strong and rapid. As a result, the equation of energy conservation is written for the RVE only.

It is written as in [8] or equivalently (for mass conservation system) as (6):

$$
\frac{\mathrm{D}}{\mathrm{D} t}(\rho h)=\underline{\underline{S}}: \underline{\underline{D}}-\nabla \cdot \underline{q}
$$

where $\rho h$ is the average enthalpy per unit volume (Figure 9):

$$
\rho h=f_{\mathrm{s}} \int_{T_{\text {ref }}}^{T} \rho_{\mathrm{s}} c_{\mathrm{ps}}\left(T^{\prime}\right) \mathrm{d} T^{\prime}+\left(1-f_{\mathrm{s}}\right) \int_{T_{\text {ref }}}^{T} \rho_{\mathrm{l}} c_{\mathrm{pl}}\left(T^{\prime}\right) \mathrm{d} T^{\prime}+\left(1-f_{\mathrm{s}}\right) \rho L^{(\mathrm{s} / \mathrm{l})}
$$

Two methods are commonly used to deal with solidification/melting phenomena. The first method uses the equivalent specific heat coefficient $c_{\mathrm{EQ}}$ as explained in Section 5.10.3.1.4. The second method uses directly [45] and [46]. For constant $c_{\mathrm{ps}}, c_{\mathrm{pl}}, \rho_{\mathrm{s} \prime}, \rho_{\mathrm{l}}$, an explicit enthalpy-temperature relationship is obtained (56). $f_{\mathrm{s}}$ is used as an independent variable and derived from mass conservation [37]. This choice allows additional complicated equations to describe temperature-enthalpy relations for metals in the semisolid state to be avoided. More details and issues concerning the numerical implementation of these two methods are given in $(11,56)$.

\subsection{Simulation and Validation}

Common commercial codes considering two-phase modeling to simulate semisolid processing do not currently exist. Development and numerical implementation of two-phase modeling considering thixotropy, heat transfer, and liquid-solid segregation are still ongoing $(14,56,59,60,63,65-67)$. They are applied to various semisolid processing routes such as thixoextrusion (66), thixoforging (56), and thixocasting (68). Liquid-solid segregation takes place at isothermal conditions and is magnified at nonisothermal conditions. The selected example for comparison between experiments and simulations is a die filling of a simple T-shape $(14,49)$. As mentioned previously, the specially designed die filling permits the continuous observation of the flow pattern. In addition, it is probably the only case for which one-phase and two-phase modeling but also isothermal and nonisothermal simulations were performed.

\subsection{Isothermal conditions}

5.10.4.1.2.1.1 Investigation of the semisolid RVE response (69)

Using micromechanics and a homogenization method of periodic structures, Geindreau and Auriault (69) determined the RVE response for semisolid considered as a porous medium constituted by a viscoplastic skeleton and saturated by an incompressible Newtonian liquid. The homogenization process permits the validation of the structure of constitutive laws proposed in the phenomenological way and discussed in Section 5.10.4.1.1.2. They also clarified conditions to get (or avoid)

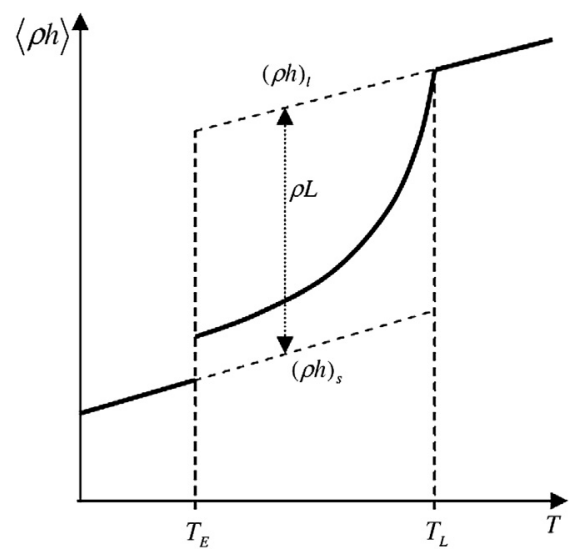

Figure 9 Typical relationship between enthalpy and temperature for a metallic alloy. $T_{\mathrm{L}}$ is the liquidus temperature. The temperature at the end of solidification is the solidus temperature $T_{\mathrm{S}}$, or the eutectic temperature $T_{\mathrm{E}}$ if a eutectic phase forms in the end of solidification, as shown here. From Rappaz, M.; Bellet, M.; Deville M. Numerical Modeling, Materials Science and Engineering, Springer Series in Computational Mathematics; Springer-Verlag: Berlin, 2003. 
liquid-solid segregation. They define two dimensionless parameters expressing the ratio of liquid and solid pressures and the ratio of liquid and solid viscosities. They demonstrated that at small processing speed (resulting in strain rate ranging between $10^{-4}$ and $10^{-1} \mathrm{~s}^{-1}$ ), liquid ejection takes place. Indeed, the intrinsic solid viscosity lies between $10^{8}$ and $10^{4} \mathrm{~Pa} . \mathrm{s}$ and is much greater than the intrinsic liquid viscosity. When the porous solid deforms, the liquid has time to flow to accommodate the overall deformation and the liquid pressure remains small. At high processing speed (strain range greater than $10 \mathrm{~s}^{-1}$ ), the intrinsic solid viscosity ranges from $10^{3}$ to 1 Pa.s. It is small and close enough to the liquid viscosity to suppress the relative displacement between the liquid and the solid; that is, segregation does not exist. As a result, when the porous solid deforms, the pressure of the liquid phase increases. Both findings are in good agreement with experiments. Kang et al. (70) also pointed out that the liquid-solid segregation is smaller with increasing strain rate. Suery and Flemings (71), Valette-Brives (72), and Rouff (73) suggested the existence of a critical strain rate above which homogeneous flow was observed. Geindreau and Auriault's analysis is given for the RVE. Liquid-solid segregation also depends on die geometry. When the liquid fluidity is high enough, an increase of the flow front surface area is easily accommodated by the liquid, promoting liquid-solid segregation (38).

\subsection{2 Investigation of the semisolid billet response during die filling $(10,14,49)$}

Numerical simulations were performed with Petera and coworkers with 'home-made' two-phase modeling software (56). The Lagrangian representation and the finite element method were used. The T-shape die realizes abrupt changes in flow direction as well as changes in cross section, because the cross section of the semisolid billet in the container is bigger than the cross section of the inlet at the bottom of the vertical duct (Figure 10). It displays a symmetric surface so that the half of the system was modeled (Figure 11). Consistently with experiments, isothermal simulations were carried out. The piston velocities were 10, 50, and $100 \mathrm{~mm} \mathrm{~s}^{-1}$. The pressure is measured with a pressure sensor, which is placed near the inlet of the vertical bar. The material under study is tin-15\%lead alloy and the solid fraction is 0.52 . Two-phase modeling was implemented. The RVE viscosity [40] is described by a Herschel-Buckley-based law modified to incorporate thixotropy (see Table 2) and solid fraction. In addition, a viscosity associated with the liquid suspended by noninteracting globules was introduced to take into account the case of completely disagglomerated solid phase $(\lambda=0)$. Parameters of the constitutive models were identified on step change in shear rate experiments as well as ramp experiments. The parameters associated with the transient behavior and the permeability of the solid phase were adjusted using an inverse method and taking into account the flow front contour, the solid fraction distribution, and the filling pressure for various piston velocities. One-phase simulation using the Herschel-Buckley law coupled with thixotropy (Table 2) was also performed.

Figure 11 shows that the experimental flow front is well reproduced with both one- and two-phase simulations for the three piston velocities. A single set of parameters was used for two-phase simulations. However, the model parameters for one-phase simulation had to be readjusted to achieve satisfactory results for different piston velocities. In addition, the one-phase simulation gives no reliable results for pressure. It predicts a nearly constant pressure while experiments and two-phase simulations show an increase of pressure until the end of the filling process (Figure 12). Figure 13 compares the experimentally obtained solid fraction and the solid fraction using the two-phase simulation. Both demonstrate liquid-solid segregation: the flow front is formed by

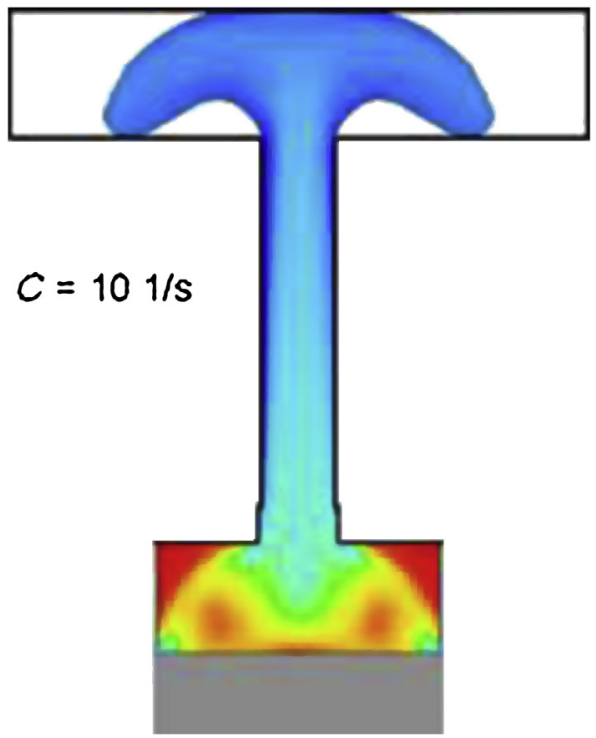

Figure 10 T-shape die: cross section of the billet $=72 \mathrm{~mm}$; cross section of the vertical duct $=20 \mathrm{~mm}$. Reproduced from Modigell, M.; Pape, L. In One Phase Fluid Dynamics Modeling, Modeling of Semi-Solid Processing, Atkinson, H. V., Ed.; Shaker-Verlag: Germany, 2008; pp 51-75 (chapter 3). 


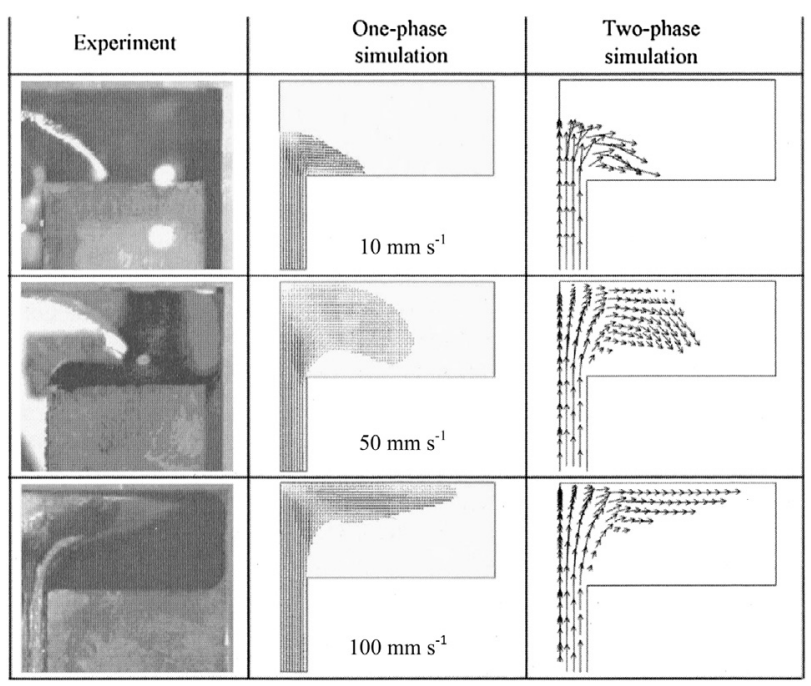

Figure 11 Isothermal experiments, one- and two-phase simulations: flow front comparison. Reproduced from Modigell, M.; Pape, L.; Vasilic, K.; Hufschmidt, M.; Hirt, G.; Shimahara, H.; Baadjou, R.; Bühnig-Polaczek, A.; Afrath, C.; Kopp, R.; Ahmadein, M.; Bünck, M. In Modeling the Flow Behavior of Semi-Solid Metal Alloys, Thixoforming: Semi-Solid Metal Processing; Hirt, G., Kopp, R., Eds.; Wiley-VCH Verlag GmbH pp 167-217 (chapter 6).

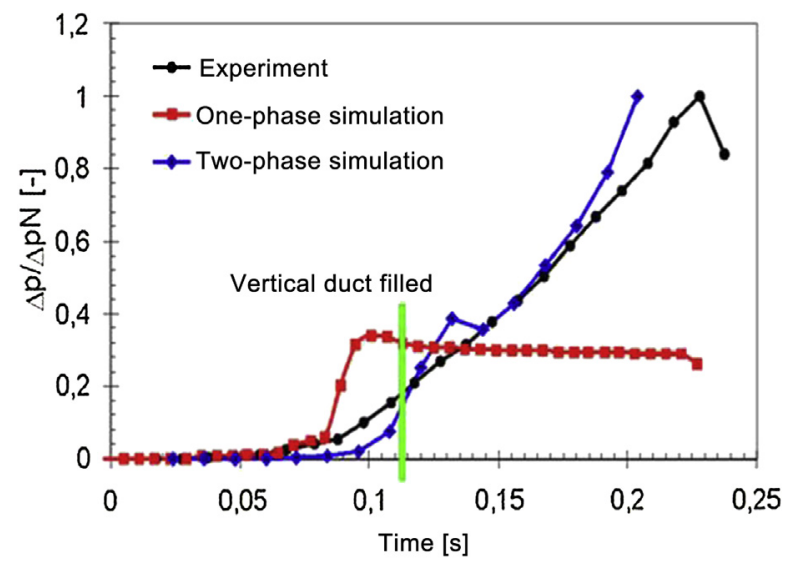

Figure 12 Measured and simulated (one-phase and two-phase) pressure at the inlet of the T-shaped die. Reproduced from Modigell, M.; Pape, L. In One Phase Fluid Dynamics Modeling, Modeling of Semi-Solid Processing; Atkinson, H. V., Ed.; Shaker-Verlag: Germany, 2008; pp $51-75$ (chapter 3).

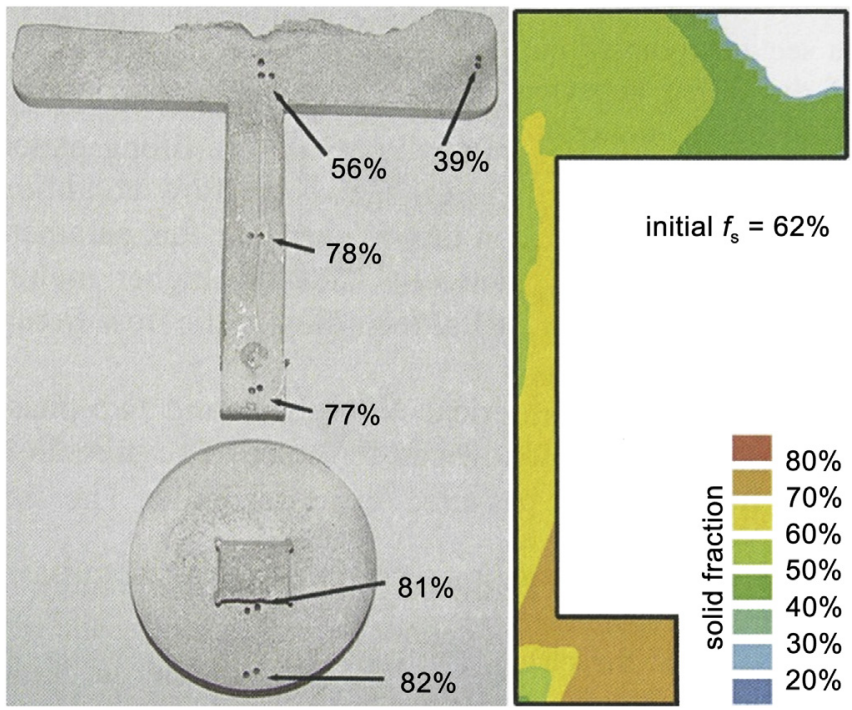

Figure 13 Segregation effects for the processing of semisolid alloys; right: experiment, left: two-phase simulation. Reproduced from Modigell, M.; Pape, L. In One Phase Fluid Dynamics Modeling, Modeling of Semi-Solid Processing; Atkinson, H. V., Ed.; Shaker-Verlag: Germany, 2008; pp 51-75 (chapter 3). 

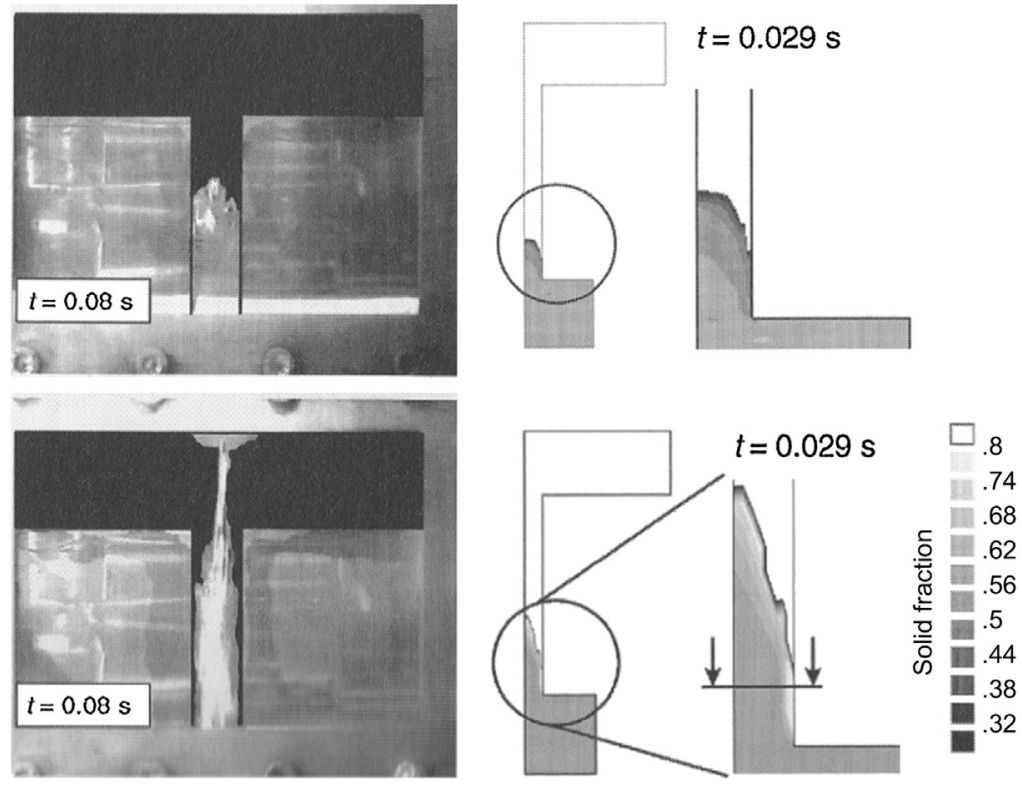

Figure 14 Flow pattern during T-shape die filling of tin-15\%lead alloy. Top: isothermal experiments (left) and two-phase simulation (right). Bottom: nonisothermal experiments (left) and two-phase simulation (right); piston velocity $=50 \mathrm{~mm} \mathrm{~s}^{-1}$, initial solid fraction $=0.52$ corresponding to a material temperature of $192^{\circ} \mathrm{C}$, die temperature $=40^{\circ} \mathrm{C}$ (for nonisothermal test). Reproduced from Modigell, M.; Pape, L.; Vasilic, K.; Hufschmidt, M.;

Hirt, G.; Shimahara, H.; Baadjou, R.; Bühnig-Polaczek, A.; Afrath, C.; Kopp, R.; Ahmadein, M.; Bünck, M. In Modeling the Flow Behavior of Semi-Solid Metal Alloys, Thixoforming: Semi-Solid Metal Processing, Hirt, G., Kopp, R., Eds.; Wiley-VCH Verlag GmbH pp 167-217 (chapter 6).

material with a low solid fraction. Consequently, the densification of solid phase in the inlet at the bottom of the vertical duct leads to a continuous increase in pressure.

\subsection{Nonisothermal conditions}

During semisolid processing, another important issue is solidification occurring on contact of the material with the die walls. Nonisothermal experiments and two-phase simulations of T-shape die filling were carried out (Figure 14). Experiments revealed that at the beginning, the semisolid flows as a thin jet with almost no contact. The flow front is less smooth and reaches the upper wall of the die earlier than in the isothermal case. Two-phase simulations qualitatively reproduce the difference for isothermal and nonisothermal cases with an optimized set of parameters. Solidification occurs in contact with the cold walls. The solidified layer reduces the free cross section, considerably increasing liquid-solid segregation. This study proves that liquid-solid segregation is magnified at nonisothermal conditions. A critical temperature above which liquid-solid segregation takes place seems to exist $(43,74)$. This critical temperature is not an intrinsic material property since its value depends on heat transfer at the wall-material interface (43).

\subsubsection{Conclusion}

Numerical simulation of semisolid processing can be carried out using one- or two-phase modeling. They are extensively developed to design the mold or the die and to determine the optimum forming conditions. One-phase modeling considers that the velocity of the solid and liquid phases are equal so cannot express solid-liquid segregation. However, for homogeneous flow conditions, it is useful to predict the flow front. More discrepancies appear on attempting to predict the forming load. Thixotropy, shear thinning, and solidification/melting phenomena can be incorporated. In practice, most commercial codes are based on the description of the steady-state semisolid response while semisolid processing involves highly transient situations. The issue of characterizing the transient regime is responsible for this difficulty. Two-phase modeling is very promising to predict and avoid liquid-solid segregation and defects located at under pressure regions. But there is still much work to be done to introduce them in computer codes. Whatever modeling, they have to cope with the issue of model parameter identification, and further specific experiments and measurements achieved on both material and processing are required.

\section{Acknowledgments}

I would like to acknowledge Docteur Adriana Neag for giving me results from simulations carried out with the commercial code FORGE2009 (F) (Figures 7 and 8), Professor Régis Bigot and Doctor Eric Becker for discussions on thixoforming and thermal effects. 


\section{References}

1. Price, J. F. Lagrangian and Eulerian Representations of Fluid Flow: Kinematics and the Equations of Motion, 2006. http://www.whoi.edu/science/P0/people/jprice; pp 1-56.

2. Gurtin, M. E. An Introduction to Continuum Mechanics; Academic Press, Inc.: New York, 1981.

3. Douglas, J. F.; Gasiorek, J. M.; Swaffield, J. A. Fluid Mechanics, 3rd ed.; Longman Scientific \& Technical, Wiley: Harlow, Essex, England, New York, 1995.

4. Chen, W. F. Constitutive Equations for Engineering Materials. In Plasticity and Modeling; Elsevier: Amsterdam, 1994; Vol. 2, pp 840-849.

5. Géradin, M.; Cardona, A. Flexible Multibody Dynamics: A Finite Element Approach; John Wiley and Sons, Ltd: Chichester, UK, 2001.

6. Rappaz, M.; Bellet, M.; Deville, M. Numerical Modeling, Materials Science and Engineering, Springer Series in Computational Mathematics; Springer-Verlag: Berlin, 2003.

7. Zenkiewicz, 0. C.; Taylor, R. L. The Finite Element Method for Solid and Structural Mechanics; Elsevier, Ltd: Oxford, UK, 2005.

8. Martin, C.; Orgéas, L. In Modélisation des procédés de mise en forme, Mise en forme des alliages métalliques à l'état semi-solide; Suery, M., Ed.; Hermès-Lavoisier: France, 2002; pp 198-221 (chapter 8).

9. Favier, D.; Orgéas, L.; Geindreau, C.; Bay, F.; Chastel, Y.; Bellet, M. In Modélisation des phénomènes de ségrégation entre phases liquide et solide, Mise en forme des alliages métalliques à l'état semi-solide; Suery, M., Ed.; Hermès-Lavoisier: France, 2002; pp 223-261 (chapter 9).

10. Modigell, M.; Pape, L. In One Phase Fluid Dynamics Modeling, Modeling of Semi-Solid Processing; Atkinson, H. V., Ed.; Shaker-Verlag: Germany, 2008; pp 51-75 (chapter 3).

11. Petera, J. In Two-Phase Approach to Modeling of Semi-Solid Processes, Modeling of Semi-Solid Processing; Atkinson, H. V., Ed.; Shaker-Verlag: Germany, 2008; pp 77-101 (chapter 4).

12. Favier, V. In Solid Approach-Fluid Approach: What Differences? Modeling of Semi-Solid Processing; Atkinson, H. V., Ed.; Shaker-Verlag: Germany, 2008; pp 105-122 (chapter 5).

13. Favier, V. In Micromechanics and Homogenization Techniques for Disordered Materials: Application to Semi-Solid Behavior, Modeling of Semi-Solid Processing; Atkinson, H. V., Ed.; Shaker-Verlag: Germany, 2008; pp 123-151 (chapter 6).

14. Modigell, M.; Pape, L.; Vasilic, K.; Hufschmidt, M.; Hirt, G.; Shimahara, H.; Baadjou, R.; Bühnig-Polaczek, A.; Afrath, C.; Kopp, R.; Ahmadein, M.; Bünck, M. In Modeling the Flow Behavior of Semi-Solid Metal Alloys, Thixoforming: Semi-Solid Metal Processing; Hirt, G., Kopp, R., Eds.; Wiley-VCH Verlag GmbH \& Co.: Germany, 2009; pp 167-217 (chapter 6).

15. Favier, V.; Bigot, R.; Cézard, P. In A Physical and Micromechanical Model for Semi-Solid Behavior, Thixoforming: Semi-Solid Metal Processing; Hirt, G., Kopp, R., Eds.; WileyVCH Verlag GmbH \& Co.: Germany, 2009; pp 221-237 (chapter 7).

16. Kirkwood, D. H.; Suéry, M.; Kapranos, P.; Atkinson, H. V.; Young, K. P. Semi-Solid Processing of Alloys. In Springer Series in Materials Science; Spinger-Verlag: Berlin, 2010; Vol. 124, p 172.

17. Atkinson, H. V. Modeling the Semisolid Processing of Metallic Alloys. Prog. Mater. Sci. 2005, 50, 341-412.

18. Ziegler, H. An Introduction to Thermodynamics; Elsevier: Amsterdam, North-Holland, 1977.

19. Balitchev, E.; Hallstedt, B.; Neuschütz, D. Thermodynamic Criteria for the Selection of Alloys Suitable for Semi-Solid Processing. Steel Res. 2005, 76, 92-98.

20. Lecomte-Beckers, J.; Rassili, A.; Robelet, M.; Poncin, C.; Koeune, R. Determination of Solidification Parameters Used for the Prediction of the Thixoformability of Several Steel Alloys. Solid State Phenom. 2006, 116-117, 54-57.

21. Einstein, A. Ann. Phys. 1911, 34, 596.

22. Batchelor, G. K. The Effect of Brownian Motion on the Bulk Stress in a Suspension of Spherical Particles. J. Fluid Mech. 1977, 83, 97-117.

23. Joly, P. A.; Mehrabian, R. The Rheology of Partially Solid Alloy. J. Mater. Sci. 1976, 11, 1393-1418.

24. Cross, M. M. Rheology of Non-Newtonian Fluids: A New Flow Equation for Pseudoplastic Systems. J. Colloid. Sci. 1965, 20, 417-437.

25. Cheng, D. V. H. Yield Stress: A Time-Dependent Property and How to Measure It. Rheol. Acta 1986, 25, 542-554.

26. Koke, J.; Modigell, M. Flow Behaviour of Semi-Solid Metal Alloys. J. Non-Newtonian Fluid Mech. 2003, 112, 141-160.

27. Cheng, D. C. H.; Evans, F. Phenomenological Characterization of the Rheological Behavior of Inelastic Reversible Thixotropic and Antithixotropic Fluids. Br. J. Appl. Phys. 1965, 16, 1599-1617.

28. Wahlen, A. Modeling the Thixotropic Flow Behavior of Semi-Solid Aluminium Alloy. Mater. Sci. Forum 2002, 396-402, 185-190.

29. Burgos, G. R.; Alexandrou, A. N.; Entov, V. Thixotropic Rheology of Semisolid Metal Suspensions. J. Mater. Process. Technol. 2001, 110, 164-176.

30. Modigell, M.; Koke, J. Rheological Modeling on Semi-Solid Metal Alloys and Simulation of Thixocasting Process. J. Mater. Process. Technol. 2001, 111, 53-58.

31. Kumar, P.; Martin, C. L.; Brown, S. Shear Rate Thickening Behavior of Semisolid Slurries. Metall. Trans. A 1993, 24, 1107-1116.

32. Kumar, P.; Martin, C. L.; Brown, S. Constitutive Modeling and Characterization of the Flow Behavior of Semi-Solid Metal Alloy Slurries - I The Flow Behavior. Acta Metall. Mater. 1994, 42, 3595-3602.

33. Martin, C. L.; Kumar, P.; Brown, S. Constitutive Modeling and Characterization of the Flow Behavior of Semi-Solid Metal Alloy Slurries - II Structural Evolution under Shear Deformation. Acta Metall. Mater. 1994, 42, 3603-3614.

34. Ito, Y.; Flemings, M. C.; Cornie, J. A. Nature and Properties of Semi-Solid Material. In Proceeding of 2nd International Conference on Semi-Solid Processing of Alloys and Composites; Brown, S. B., Flemings, M. C., Eds.; Cambridge, MA, USA, 1992; pp 3-17.

35. Perez, M.; Barbe, J. C.; Neda, Z.; Brechet, Y.; Salvo, L. Computer Simulation of the Microstructure and Rheology of Semi-Solid Alloys under Shear. Acta Mater. 2000, 48, 3773-3782.

36. Favier, V.; Cezard, P.; Bigot, R. Transient and Non-Isothermal Semi-Solid Behaviour: 3D Micromechanical Modeling. Mater. Sci. Eng. A 2009, 517, 8-16.

37. Favier, V.; Atkinson, H. V. Micromechanical Modelling of the Elastic-Viscoplastic Response of Metallic Alloys under Rapid Compression in the Semi-Solid State. Acta Mater. 2011, 59, 1271-1280.

38 Neag, A.; Favier, V.; Bigot, R.; Pop, M. Microstructure and Flow Behavior during Backward Extrusion of Semi-Solid 7075 Aluminium Alloy. J. Mater. Process. Technol. 2012, $212,1472-1480$.

39. Liu, T. Y.; Atkinson, H. V.; Kapranos, P.; Kirkwood, D. H.; Hogg, S. C. Rapid compression of aluminum alloys and its relationship to thixoformability. Metallurgical Transactions, A 2003, 34, 1545-1554.

40. Koeune, R.; Ponthot, J. P. An Improved Constitutive Model for the Numerical Simulation of Semi-Solid Thixoforming. J. Comput. Appl. Math. 2010, 234, 2287-2296.

41. Vaneetveld, G.; Rassili, A.; Atkinson, H. V. Influence of Parameters during Induction Heating Cycle of 7075 Aluminium Alloys with RAP Process. Solid State Phenomena 2008, 141-143, 719-724.

42. Hirt, G.; Baadjou, R.; Knauf, F.; Seidl, I.; Shimahara, H.; Abel, D.; Kopp, R.; Gasper, R. Schönbohm, Thixoforging and Rheoforging of Steel and Aluminium Alloys. In Thixoforming, Semi-solid Metal Processing; Hirt, G., Kopp, R., Eds.; Wiley-VCH Verlag GmbH \& Co.: Germany, 2009; pp 369-409 (chapter 10).

43. Becker, E.; Favier, V.; Bigot, R.; Cézard, P.; Langlois, L. Impact of Experimental Conditions on Material Response during Forming of Steel in Semi-Solid State. J. Mater. Process. Technol. 2010, 210, 1482-1492.

44. Becker, E.; Bigot, R.; Langlois, L. Thermal Exchange Effects on Steel Thixoforming Processes. Int. J. Adv. Manuf. Technol. 2010, 48, 913-924.

45. Paradies, C. J.; Rappaz, M.; Imwinkelried, T.; Gabathuler, J. P. Simulation of the Pressure Die Casting of a Thixotropic Aluminium Alloy. In Proceeding of 4th International Conference on Semi-Solid Processing of Alloys and Composites; Sheffield, UK, 1996, pp 115-119.

46. Koke, J.; Hufschmidt, M.; Modigell, M.; Heine, C.; Han, S.; Stapf, S.; Petera, J. Segregation and Wall Slip in Semi-Solid Alloys: Measurement, Modeling and Simulation. In Proceeding of 6th International Conference on Semi-Solid Processing of Alloys and Composites; Turin, Italy, 2000, pp 623-628. 
47. Ferziger, J. H.; Peric, M. Computational Methods for Fluid Dynamics, 2nd ed.; Springer-Verlag: Berlin Heidelberg, New York, 1997.

48. Ward, P. J.; Atkinson, H. V.; Kirkwood, D. H.; Chin, S. B. Final Report for Engineering and Physical Sciences Research Council Project 'Modeling Thixotropic Flow of Metal Alloys into a Die' (GR/M17334/01), 2002. http://www.le.ac.uk/engineering/staff/atkinson_files/modeling_final_report.pdf.

49. Hufschmidt, M.; Modigell, M.; Petera, J. Modeling and Simulation of Forming Processes of Metallic Suspensions under Non-Isothermal Conditions. J. Non-Newtonian Fluid Mech. 2006, 134, 16-26.

50. Neag, A. Simulation of filling test with $90^{\circ}$ flow path change, Private Communication, 2012.

51. Coussy, 0. Mécanique des milieux poreux; Edition Technip: Paris, 1991.

52. Truesdell, C.; Toupin, R. The Classical Field Theories. In Encyclopedia of Physics, Flugge, S., Ed.; Spinger-Verlag: Berlin, 1960; Vol. III/1, pp 226-744.

53. Bowen, R. M. In Continuous Physics III-Mixture Theory; Eringen, A. C., Ed.; Academic Press: New York, 1976; pp 1-127.

54. Patankar, S. V. Numerical Heat Transfer and Fluid Flow; Taylor and Francis: New York, 1980.

55. De Boer, R. Contemporary Progress in Porous Media Theory. Appl. Mech. Rev. 2000, 53, 323-371.

56. Petera, J.; Kotynia, M. The Finite Element Model of Non-Isothermal Semi-Solid Fluid Flow. Int. J. Heat Mass Transfer 2004, 47, $1483-1498$.

57. Terzaghi, K. Theoretical Soil Mechanics; Wiley and Sons: New York, 1943.

58. Charreyron, P. 0.; Flemings, M. C. Rheology of Semi-Solid Dendritic Sn-Pb Alloys at Low Strain Rates: Application to Forming Process. Int. J. Mech. Sci. 1985, 27, 781-791.

59. Lalli, L. A. A Model for Determination and Segregation of Solid-Liquid Mixtures. Metall. Trans. A 1985, 16, 1393-1403.

60. Gebelin, J. C.; Favier, D.; Suéry, M. Comparison of One and Two-Phase Approaches for Numerical Simulation of Semi-Solid Processing. In Proceeding of 5th ICSSPAC; Bhasin, A. K.; et al., Eds.; Golden, Colorado, USA, 1998, pp 309-316.

61. Nguyen, T. G.; Favier, D.; Suéry, M. Theoretical and Experimental Study of the Isothermal Mechanical Behavior of Alloys in the Semi-Solid State. Int. J. Plast. 1994, 10, 663-693.

62. Martin, C. L.; Favier, D.: Suéry, M. Viscoplastic Behavior of Porous Metallic Materials Saturated with Liquid, Part I: Constitutive Equations. Int. J. Plast. 1997, 13, 237-259.

63. Zavaliangos, A. Modeling of the Mechanical Behavior of Semisolid Metallic Alloys at High Volume Fractions of Solid. Int. J. Mech. Sci. 1998, 40, 1029-1041.

64. Martin, C. L.; Favier, D.; Suéry, M. Fracture Behaviour in Tension of Viscoplastic Porous Metallic Materials Saturated with Liquid. Int. J. Plast. 1999, 15, $981-1008$.

65. Kan, C. G.; Jung, H. K. Finite Element Analysis with Deformation Behavior Modeling of Globular Microstructure in Forming Process of Semi-Solid Materials. Int. J. Mech. Sci. 1999, 41, 1423-1445.

66. Choi, J. C.; Park, J. H.; Kim, B. M. Finite Element Analysis of the Combined Extrusion of Semi-Solid Materials and Its Experimental Verification. J. Mater. Process. Technol. 2000, 105, 49-54

67. Yoon, J. H.; Im, Y. T.; Kim, N. S. Finite Element Modeling of the Deformation Behavior of Semi-Solid Materials. J. Mater. Process. Technol. 2001, 113, 153-159.

68. Pineau, F.; D'Amours, G. Prediction of Shear-Related Defect Locations in Semi-Solid Casting Using Numerical Flow Models. Trans. Nonferrous Met. Soc. China 2010, 20, s878-s882.

69. Geindreau, C.; Auriault, J. L. Investigation of the Viscoplastic Behaviour of Alloys in the Semi-Solid State by Homogenization. Mech. Mater. 2009, 31, 535-551.

70. Kang, C. G.; Choi, J. S.; Kim, K. H. The Effect of Strain Rate on Macroscopic Behavior in the Compression Forming of Semi-Solid Aluminium Alloy. J. Mater. Process. Technol. 1999, 88, 159-168.

71. Suery, M.; Flemings, M. C. Effect of Strain Rate on Deformation Behaviour of Semi Solid Dendritic Alloys. Metall. Trans. A 1982, 13, 1809-1819.

72. Valette-Brives, E. Mise en forme d'aciers à l'état semi-solide: étude expérimentale et modélisation. PhD Thesis, Ecole Nationale Supérieure de Mines de Paris/Ecole Nationale Supérieure de Mines de Saint-Etienne, France, 1992.

73. Rouff, C. Contribution à la caractérisation et à la modélisation du comportement d'un acier à l'état semi-solide. Application au thixoforgeage, PhD Thesis, ENSAM, Metz, 2003.

74. Kopp, R.; Shimahara, H.; Schneider, J. M.; Kurapov, D.; Telle, R.; Munstermann, S.; Lugscheider, E.; Bobzin, K.; Maes, M. Characterization of Steel Thixoforming Tool Materials by High Temperature Compression Tests. Steel Res. Int. 2004, 75, 569-576.

75. Laxmanan, V.; Flemings, M. C. Deformation of Semi-Solid Sn-15 pct Pb Alloy. Metall. Trans. A 1980, 11, 1927-1937.

76. Turng, L. S.; Wang, K. K. Rheological Behaviour and Modelling of Semi-Solid Sn-15\% Pb Alloy. J. Mater. Sci. 1991, 26, $2173-2183$.

77. McLelland, A. R. A. PhD Thesis, University of Sheffield, Sheffield, UK, 1993.

78. Liu, T. Y. PhD Thesis, University of Sheffield, Sheffield, UK, 2002. 